\title{
AGE DIFFERENCES IN REWARD-MOTIVATED ATTENTION: BEHAVIOURAL AND ERP EVIDENCE
}

By

\author{
Farrah Kudus, Bachelor of Science (Honours) \\ McMaster University, 2016
}

\author{
A thesis \\ presented to Ryerson University \\ in partial fulfillment of the \\ requirements for the degree of \\ Master of Arts \\ in the program of \\ Psychology \\ Toronto, Ontario, Canada, 2018 \\ (C) Farrah Kudus 2018
}




\section{AUTHOR'S DECLARATION FOR ELECTRONIC SUBMISSION OF A THESIS}

I hereby declare that I am the sole author of this thesis. This is a true copy of the thesis, including any required final revisions, as accepted by my examiners.

I authorize Ryerson University to lend this thesis to other institutions or individuals for the purpose of scholarly research.

I further authorize Ryerson University to reproduce this thesis by photocopying or by other means. In total or in part, at the request of other institutions or individuals for the purpose of scholarly research.

I understand that my thesis may be made electronically available to the public. 


\begin{abstract}
Master of Arts, 2018

Farrah Kudus

Psychology

Ryerson University
\end{abstract}

Age Differences in Reward-Motivation Attention: Behavioural and ERP Evidence

The attentional system is comprised of three networks: alerting, orienting, and executive control, all of which are associated with unique neural systems. Research examining motivationcognition interactions implicate the dopaminergic and locus-coeruleus norepinephrine systems in attentional and motivational processes, both of which show age differences. The current study was conducted to explore the mechanisms through which gain and loss motivation affect attention across the lifespan, using behavioural and electrophysiological markers of attentional networks. Younger adults (18-33 years) and older adults (65-80 years) completed an incentivized version of the Attention Network Test. Our behavioural results showed age differences in incentive sensitivity, such that responses were modulated as a function of incentives. We also examined cue-N1, target-N1, and target-P3, which showed transient incentive-based modulation, and depended on incentive valence. Overall, our study provides evidence for age-related differences in the modulation of attentional networks, and contributes new insights into the mechanisms behind motivation-cognition interactions.

Keywords: Attention Network Test, Motivation, Incentives, Cognitive Aging, Alerting, Executive Control 


\section{Acknowledgements}

First, I would like to thank Dr. Julia Spaniol for her outstanding guidance throughout this project, and for her unwavering encouragement through my Master's degree. In addition, I'd like to extend all of my gratitude to Carson Pun for the incredible amount of help, and reassurance with the technical details of this project. It is also my pleasure to extend many thanks to my supervisor committee members, Dr. Ben Dyson, and Dr. Meg Moulson, for their helpful input and suggestions along the way, as well as Dr. Lixia Yang for being part of my examining committee. Lastly, I would like to sincerely thank all of my loving friends and family for listening to me endlessly talking about my thesis for the past two years - even if they weren't always fully listening. I couldn't have done this without their unwavering support. 


\section{Table of Contents}

Abstract iii

Acknowledgements $\quad$ iv

Chapter 1: Introduction and Theoretical Background 1

1.1 Attention Networks 1

1.2 Attention Network Test 2

$\begin{array}{ll}1.3 \text { Age differences in the ANT } & 3\end{array}$

$\begin{array}{ll}1.4 \text { Motivation } & 6\end{array}$

$\begin{array}{ll}\text { Chapter 2: The Current Study } & 12\end{array}$

$\begin{array}{ll}2.1 \text { Method } & 14\end{array}$

2.2 Results 23

$\begin{array}{ll}\text { Cue-related ERPs } & 28\end{array}$

Summary of incentive effects on cue-locked ERP results 29

$\begin{array}{ll}\text { Target-related ERPs } & 29\end{array}$

Summary of incentive effects on target-locked ERP results 31

$\begin{array}{ll}\text { Chapter 3: Discussion } & 32\end{array}$

3.1 Relationship Between Alerting and Incentive Effects 33

3.2 Age Differences in Sensitivity to Gains versus Losses

3.3 Incentive-Based Modulation of Attention Networks 35

3.4 Age differences in Attention Networks

3.5 Limitations and Future Directions 38

$\begin{array}{ll}3.6 \text { Conclusion } & 39\end{array}$

$\begin{array}{ll}\text { Tables } & 41\end{array}$ 
Figures

Appendices

References 


\section{List of Tables}

Table 1: Group characteristics $\quad 54$

Table 2: Means (M) and standard deviations (SD) for behavioural data 55

Table 3: Effects of age group and task conditions on accuracy 56

Table 4: Effects of age group and task conditions on reaction time 57

Table 5: Effects of age group and task conditions on inverse efficiency 58

Table 6: Effects of age group and task conditions on cue-locked N1 59

Table 7: Effects of age group and task conditions on target-locked N1 60

Table 8: Effects of age group and task conditions on target-locked P3 61 


\section{List of Figures}

$\begin{array}{ll}\text { Figure 1: Incentivized ANT } & 62\end{array}$

$\begin{array}{ll}\text { Figure 2: Accuracy for younger and older adults } & 63\end{array}$

$\begin{array}{ll}\text { Figure 3: Mean reaction time for correct responses } & 64\end{array}$

$\begin{array}{ll}\text { Figure 4: Inverse efficiency for younger older adults } & 65\end{array}$

Figure 5: Relationship between incentive effects and alerting effects 66

Figure 6: Averaged cue-locked waves at occipital and parietal sites for YA 67

Figure 7: Averaged cue-locked waves at occipital and parietal sites for OA 68

Figure 8: Averaged cue-locked waves at occipital and parietal sites for YA 69

Figure 9: Averaged cue-locked waves at occipital and parietal sites for OA 70

Figure 10: Mean cue-N1 amplitudes collapsed across age groups 71

Figure 11: Target-locked waves at occipital and parietal electrodes for YA 72

Figure 12: Target-locked waves at occipital and parietal electrodes for YA 73

Figure 13: Target-locked waves at posterior electrodes for YA $\quad 74$

Figure 14: Target-locked waves at posterior electrodes for OA $\quad 75$

Figure 15: Mean target-N1 amplitudes for all participants 76

Figure 16: Target-locked waves at frontocentral and centroparietal electrodes for YA 77

Figure 17: Target-locked waves at frontocentral and centroparietal electrodes for OA 78

Figure 18: Target-locked waves at frontocentral and centroparietal electrodes for YA 79

Figure 19: Target-locked waves at frontocentral and centroparietal electrodes for OA $\quad 80$

Figure 20: Mean target-P3 amplitudes for younger and older adults $\quad 81$ 


\section{List of Appendices}

Appendix A: Demographics $\quad 82$

$\begin{array}{ll}\text { Appendix B: MMSE } & 83\end{array}$

Appendix C: Mill Hill Vocabulary Scale $\quad 84$

Appendix D: Digit Symbol $\quad 86$

$\begin{array}{ll}\text { Appendix E: BIS/BAS } & 87\end{array}$

$\begin{array}{ll}\text { Appendix F: PANAS } & 88\end{array}$

Appendix G: DASS 21 
Age Differences in Reward-Motivated Attention: Behavioural and ERP Evidence

\section{Chapter 1: Introduction and Theoretical Background}

Attention is crucial to a range of tasks, from simply reading a book to driving on a busy highway. The ability to selectively attend to stimuli is thought to be dependent on an individual's inhibitory control. Inhibitory control is an executive function that allows people to limit their intake of sensory information through the suppression of irrelevant stimuli (Hasher \& Zacks, 1988). Aging is associated with decreased inhibitory control (Lustig, Hasher, \& Zacks, 2007). Motivational incentives can enhance an individual's ability to allocate their attention (Pessoa \& Engelmann, 2010). However, there is limited research that examines age differences in the motivational modulation of attention. The current study contributed to this burgeoning literature by examining age differences in reward-motivated attention with behavioural and neural measures.

\subsection{Attention Networks}

A seminal study by Petersen and Posner (1990) describes the human attentional system as encompassing three attentional networks: alerting, orienting, and executive control. Alerting is the network concerned with readiness and maintaining vigilance in preparation for a stimulus. The alerting network is associated with the locus-coeruleus norepinephrine (LC-NE) system (Posner \& Petersen, 1990; Xuan et al., 2016). Second, orienting is the network associated with preparation (e.g., eye or head shifts) in response to sensory input. It involves the neurotransmitter acetylcholine, and neural regions such as the temporoparietal junction, frontal eye fields, and parietal cortex (Fan, 2005). The executive control network is involved in conflict resolution and inhibitory control and involves areas of the prefrontal cortex and anterior cingulate cortex, and 
dopamine is often implicated in the functioning of this network (Petersen \& Posner, 2012;

Braver \& Cohen, 2000).

\subsection{Attention Network Test}

The Attention Network Test (ANT; Fan, McCandliss, Sommer, Raz, \& Posner, 2002) was developed to measure the alerting, orienting, and executive control networks. The ANT is a combination of the Eriksen Flanker task (Eriksen \& Eriksen, 1974) and the attentional cueing paradigm (Posner, 1980). The goal is to identify whether a central arrow, which appears either above or below a central fixation cross, is pointing left or right. The central arrow is flanked by four other arrows (two to the left, two to the right). The flanker arrows may be congruent (i.e., pointing in the same direction as the central arrow), incongruent (i.e., pointing in the opposite direction of the central arrow), or neutral (i.e., straight lines). Prior to the onset of the target, some trials feature temporal and spatial cues that are predictive of the temporal onset and location of the target, which allows researchers to measure the efficiency of network effects of the alerting and orienting networks, respectively. The ANT cue conditions include no cue (no cue, only a fixation cross), spatial cue (cue presented in the target location), centre cue (uninformative centrally-located cue), and double cue (two cues presented at both potential target locations). The alerting network is measured by comparing reaction times for trials preceded by a temporal alerting cue (i.e., double cue) to those without an alerting cue (i.e., no cue). The orienting network is measured by comparing reaction times for trials that are preceded by an informative spatial orienting cue (i.e., spatial cue) to those with an uninformative orienting cue (i.e., centre cue). Lastly, the efficiency of the executive control network is measured by comparing trials with incongruent as compared to congruent flankers. Responses are faster when an alerting cue is present, when a spatial cue is present, and when flankers are congruent. 


\subsection{Age differences in the ANT}

Behavioural results. Behavioural studies have yielded mixed findings with regard to age differences in attention networks. Generally, behavioural results regarding the orienting network seem to be robust, such that the orienting network seems to be preserved in aging (Gamboz et al., 2010; Jennings, Dagenbach, Engle, \& Funke, 2007).

However, the findings that examine the effect of aging on the alerting and executive control networks are more ambiguous (Fernandez-Duque \& Black, 2006; Gamboz et al., 2010; Jennings, Dagenbach, Engle, \& Funke, 2007). For example, in two studies, older adults performed similarly to younger adults in terms of the orienting and executive control networks effects, but showed reduced efficiency of the alerting network (Jennings et al., 2007; Kaufman, Sozda, Dotson, \& Perlstein, 2016). In contrast, in another study, alerting showed an age-related enhancement (Fernandez-Duque \& Black, 2006). Despite findings that the executive control network is preserved in aging (Gamboz et al., 2010), it has also been demonstrated that an increase in age is associated with a deterioration of the executive control network (Mahoney, Verghese, Goldin, Lipston, \& Holtzer, 2010).

These varied findings may occur due to differences in tasks and analyses. For example, older adults show a generalized slowing in cognitive tasks in comparison to younger adults (Verhaeghen \& De Meersman, 1998), as well as employing different response strategies, such that they prioritize accuracy over RT, whereas younger adults often show the opposite trend (Forstmann et al., 2011). Some researchers examine age differences after correcting for agerelated slowing (e.g., Gamboz et al., 2010), whereas others do not. Additionally, studies vary the length of cue presentation, which may affect the interpretation of alerting and orienting findings (Kaufman et al., 2016). 
ERP results. Event-related potentials (ERPs) provide fine (millisecond-level) temporal details about cognitive processes. Due to their temporal precision, ERPs can help shed light on processes underlying behavioural data. By averaging potentials and time-locking them to certain events (i.e., visual stimuli), researchers are able to examine fluctuations in voltage, and ERP components associated with certain cognitive events (Luck, 2014). By time-locking analyses to visual cue and targets, studies are able to infer activity based on those stimuli.

To our knowledge, only four prior studies have combined the ANT with electroencephalography (EEG) in order to explore event-related potentials related to visual attention. Neuhaus et al. (2010) highlighted the behavioural differences in the three networks, and examined two cue-locked ERP components: parietal and occipital target-N1 and frontal and parietal P3. The N1 is an early negative deflection, which occurs roughly between $150-250 \mathrm{~ms}$ after a stimulus. Neuhaus et al. (2010) found it to be associated with the orienting and alerting networks. On the other hand, target-locked P3 is a later positivity that generally occurs around 400-700ms post-stimulus, and is associated with the executive control network and inhibitory processes. The amplitude of the $\mathrm{P} 3$ decreases in the presence of incongruent flankers (Neuhaus et al., 2010).

Galvao-Carmona et al. (2014) explored the contingent negative variation (CNV), along with target-locked $\mathrm{P} 1, \mathrm{~N} 1$, and $\mathrm{P} 3$. CNV is a component associated with increases in amplitude following the presence of a warning cue, a change that is exacerbated when the warning cue includes more (i.e., spatial and temporal) information. When examining target-locked components, amplitudes of $\mathrm{N} 1$ and $\mathrm{P} 1$ have been shown to increase with the presentation of a cue in an attended-to location (Posner \& Dehaene, 1994), and both showed effects of alerting. 
Following up on the prior two studies that focused on younger adults, Kaufman et al. (2016) investigated age-related differences and supplemented unclear behavioural findings with ERPs. The researchers were also interested in how ERPs would line up with behavioural findings that were corrected or uncorrected for age-related slowing. Based on Neuhaus et al. (2010), target-locked posterior N1 and target-locked parietal P3 were examined. At target-N1, younger exhibited larger N1 amplitudes in the double cue conditions (relative to no cue), demonstrating an effect of alerting. Also during target presentation, older adults showed decreased P3 amplitudes, but this did not vary as a function of congruency, as both younger and older adults showed decreased P3 amplitudes for incongruent targets.

Similarly, Williams et al. (2016) combined the ANT with ERP to shed light on agerelated differences in the three networks using the two prior younger adult studies. They found behavioural age differences in the alerting, but a similar pattern of behavioural results in older and younger adults with regards to the orienting and executive control networks. Williams and colleagues' (2016) behavioural results were consistent with previous findings exploring age differences on the ANT (e.g., Jennings et al., 2007; Gamboz et al., 2010; Kaufman et al., 2016), but their ERP results both complemented and qualified their findings. ERP results revealed that components related to alerting and orienting (e.g., P1, N1, and CNV) did not show a difference between younger and older adults, which ran counter to the behavioural age differences found in alerting. In addition, in contrast to their behavioural findings, an ERP component that was analyzed $-\mathrm{P} 3$-related to the executive control network did show a significant difference among the age groups.

It was suggested that this contradictory finding - that ERP components associated with alerting did not show the age difference that was demonstrated behaviourally—might be due to 
differential behavioural interactions (e.g., MacLeod, Lawrence, McConnell, Eskes, Klein, \& Shore, 2010) between the alerting and executive control networks in older and younger adults. That is, older adults generally focus on accuracy rather than speed, whereas younger adults tend to prioritize responding faster rather than accurately.

Though behavioural and ERP results seem to be contradictory, these studies provided a valuable demonstration of how ERPs can be used interpret behavioural measures from the ANT. That is, electrophysiological measures can help examine neural correlates of attentional networks in a way that behavioural measures are not able to. For example, this allows us to examine activity independent of behaviour. Additionally, examining ERPs at both cue and target stimuli allows a more detailed understanding of the sequence of effects elicited by the stimuli. Of particular relevance to the current study is how attentional networks are affected by motivation. When combining motivational cues with an attentional test, the temporal sensitivity of ERPs can provide insight into the interplay between neurotransmitter systems associated with these networks (i.e., LC-NE, acetylcholine, dopamine). This can provide information about when attentional and motivational processes begin to diverge across younger and older adults, and aid in investigating neural underpinnings in order to further examine age-related differences in attentional networks.

\subsection{Motivation}

Motivation - an affective state that promotes goal-directed behaviour (Chiew \& Braver, 2011) - can modulate cognitive functioning in both younger and older adults (Braver et al., 2014; Yee \& Braver, 2018). The goal-directed nature of cognition is essential in that it allows individuals to achieve their goals and act both effectively and efficiently in everyday life. In cognitive tasks that require attention, introducing motivational incentives supports goal pursuit 
by selectively allocating attentional resources to the relevant task (Pessoa \& Engelmann, 2010).

This enhanced cognition in the presence of reward is a consistent finding, wherein task performance is enhanced when an incentive is introduced (e.g., Chiew and Braver, 2011;

Engelmann \& Pessoa, 2007). In a laboratory setting, experimentally manipulating motivation is often achieved by framing incentives in a gain or loss context (i.e., allowing participants to either maximize potential gains, or to minimize potential losses). Often, social or financial rewards are used as incentives (e.g., Samanez-Larkin et al, 2007). Older adults and younger adults seem to differ in their sensitivity to certain rewards, depending on factors such as type (e.g.; social or financial; Rademacher, Salama, Gründer, \& Spreckelmeyer, 2014), frame (gain or loss; Ebner, Freund, \& Baltes, 2006; Samanez-Larkin et al., 2007), and magnitude (Engelmann, Damaraju, Padmala, \& Pessoa, 2009; Samanez-Larkin et al., 2007). Moreover, a growing body of literature suggests that motivational incentives may have both transient (i.e., trial-by-trial) and/or sustained (i.e., context-dependent) effects on cognitive abilities. The difference in transient versus sustained incentive-based modulation has been demonstrated in both behavioural (e.g., Marini, van den Berg, \& Woldorff, 2015) and physiological measures (e.g., Jimura, Locke, \& Braver, 2010; Chiew \& Braver, 2013), but there is limited information on the time course of incentive effects in older adults.

Motivation and aging. The influence of incentives on cognitive functions shows agerelated change. Studies have shown age-related differences in response to rewards depending on incentive type. For example, social rewards elicit stronger responses from older adults when compared to younger adults, who tend to show a stronger response to financial rewards (Rademacher et al., 2014). Moreover, younger and older adults may differ in their sensitivity towards positive (e.g., motivation to seek gains) versus negative (e.g., motivation to avoid losses) 
rewards (Ebner, et al., 2006; Samanez-Larkin et al., 2007). However, interpretations of these findings have varied. For example, Depping and Freund (2012) suggest that lifespan changes in goal orientation can affect the valuation of gains and losses. As a result, as adults age, their goal orientation should focus more on minimizing losses rather than maximizing gains. Thus, older adults should be more motivated by incentives that are framed in a "loss" context. However, other studies have reported a well documented "positivity bias" in older adults (e.g., Mather \& Carstensen, 2005; Samanez-Larkin et al., 2007; Nielsen, Knutson, \& Carstensen, 2008), where older adults show a preference for positively valenced information. Studies using neuroimaging (Samanez-Larkin et al., 2007) and event-related potentials (ERPs; Kisley, Wood, \& Burrows, 2007) have shown that this positivity effect seems to be robust across these brain-based - as well as behavioural - measures.

Psychological theories. Several findings have shown that gain- and loss- incentives motivate younger and older adults differently. The age differences observed in gain and loss motivation over the lifespan may be related—or explained by—age differences in goal orientation. For example, Samanez-Larkin et al. (2007), using functional magnetic resonance imaging (fMRI), found that neural activation in younger and older adults was similar when they were anticipating gains. In contrast, however, younger adults showed increased neural activation in anticipation of losses, but older adults did not. Specifically, older adults showed less activation in both the insula and caudate during losses but showed increased activation in those areas for gains. The study presented an asymmetry in the valuation of gains and losses between older and younger adults, such that older adults may experience less negative arousal in anticipation of negative events. However, the reduction in arousal from expecting negative outcomes may not be a completely robust finding, as older adults have also been shown to focus on preventing 
losses in comparison to younger adults, who tend to work towards gains (Ebner, Freund, \& Baltes, 2006). Results are still unclear and under examination, and so age-related changes in cognition are often interpreted through the contrasting lens of the well-documented positivity bias demonstrated by older adults (Mather \& Carstensen, 2005; Samanez-Larkin et al., 2007; Spaniol, et al., 2008).

The positivity effect is a phenomenon where older adults tend to have a focus on positive information relative to negative or neutral information (Mather \& Carstensen, 2005). It can be explained within the framework of the socioemotional selectivity theory (SST; Carstensen, Isaacowitz, \& Charles, 1999). According to this theory, the motivational goals of individuals change over their lifespan, and they tend to rely more on affective information as they grow older. That is, as people age, they see their time becoming increasingly limited, and so they attempt to prioritize their socioemotional well-being, which begin to take precedence over goals that are oriented towards the future, such as gaining knowledge. The motivational shift towards positive information also seems to affect cognitive processing, as healthy older adults seem to selectivity allocate more attention to positive information compared to negative information (Mather \& Carstensen, 2003; Isaacowitz, Wadlinger, Goren, \& Wilson, 2004).

Although findings regarding attentional differences and how they relate to the positivity effect are not entirely conclusive (Charles, Mather, \& Carstensen, 2003; Reed, Chan, \& Mikels, 2014), a neurobiological perspective may help contribute to our understanding of age-differences in motivated attention.

Neural mechanisms. Dopamine is a key neurotransmitter associated with the brain's reward network, and is traditionally implicated in age-related differences in sensitivity to reward (Sara, 2009). Thus, age-related differences in reward processing are often attributed to an age- 
related dopaminergic decline, which is in part due to loss of striatal dopamine receptors that occurs in healthy aging (Chowdhury et al., 2013; Eppinger, Nystrom, \& Cohen, 2012; Wang et al., 1998). Dopaminergic decline may result in reduced sensitivity to incentives and the inability to learn from reward. However, findings are mixed, and a deficit in incentive processing may not occur across-the-board. That is, age-related differences in the reward system may depend on the type of incentive (e.g., Samanez-Larkin et al., 2007), or older adults may use compensatory neural mechanisms (e.g., Spaniol, Bowen, Wegier, \& Grady, 2015).

Although the neurotransmitter most often associated with reward processing is dopamine, the LC-NE system also plays a role in the effects of reward on attention through its association with the reward network. The LC is a small nucleus in the brainstem, and is the main source of norepinephrine release in the brain (Aston-Jones \& Cohen, 2005). Despite the LC being most often associated with regulatory processing of attention and arousal (Sara, 2009; Sara \& Bouret, 2012), studies have begun to show that through two unique modes of firing, the LC-NE system plays a vital part in goal-directed attentional processes and is implicated in the reward circuit (Hofmeister \& Sterpenich, 2015). To help clarify the relationship between the LC-NE, attention, and motivation, studies generally use behavioural and physiological markers of NE release in the brain. Similar to the dopaminergic response, the LC-NE system is sensitive to reward magnitude (Bouret, 2012). In addition, the LC-NE system supports goal-oriented behaviour by regulating individuals' inclination to exploit (i.e., increasing task performance), or explore (i.e., withdrawing from task performance) their attention depending on task demands (Aston-Jones \& Cohen, 2005). NE activity may be measured using behavioural measures (Williams, Biel, Dyson, \& Spaniol, 2017), event-related potentials (ERPs; Neuhaus et al., 2010; Murphy, Robertson, 
Balsters, \& O’Connell, 2011; Galvao-Carmona et al., 2014), or pupil dilation (Chiew \& Braver, 2013; Gilzenrat, Nieuwenhuis, Jepma, \& Cohen, 2010; Joshi, Li, Kalwani, \& Gold, 2016).

Adaptive gain theory. In order to explain the relationship between NE release and motivation, adaptive gain theory (Aston-Jones \& Cohen, 2005) suggests that motivation affects the release of NE in the brain through different modes of firing. The release of NE occurs in two modes of activation, 1) phasic, and 2) tonic. It has been suggested that prefrontal areas moderate fluctuations between these two modes of release, and is dependent on the relative utility (i.e., determined by the current costs and reward) of a task. The tonic mode of firing draws an individual away from task performance (i.e., explore), whereas the phasic mode of firing optimizes an individual towards task performance (i.e., exploit). That is, depending on the utility of a task, prefrontal areas will result in either a tonic or phasic mode of release. According to this theory, if motivational states directly alter modes of release, individuals that are more motivated will be concerned with optimizing task performance, and will engage phasic firing. On the other hand, individuals who are not motivated in the moment will engage the tonic mode of release, resulting in disengagement from the current task. Through this adjustment based on the relative benefits of a task, the different modes of release of NE helps to improve the balance of exploration and exploitation in order to optimize performance and reward. The recruitment of the phasic release of NE has been previously linked to behavioural measures of phasic alerting. The alerting response associated with a phasic release of NE seems to be linked to the alerting network captured by the Attention Network Test (ANT; Aston-Jones \& Cohen; Xuan et al., 2016).

In summary, incentivizing an attentional task may allow the adaptive gain theory to shed light on the mechanisms by which motivational incentives affect attention differentially across 
the lifespan. Specifically, the LC-NE system and its association with the reward network and dopamine may contribute to age-related changes in why and how these changes occur. Taken together, there are several factors that affect an individual's incentive processing. Theories of goal orientation and motivational change across the lifespan such as the SST have been able to account for some of the observed effects. Other research has explored physiological mechanisms such as the dopamine and LC-NE systems as candidates for explaining these findings. However, to our knowledge, no current theory has been able to fully account for mixed findings in the literature on incentive processing and aging.

Attention network test and reward-based motivation. Few studies have examined the impact of reward on attention across age groups. Williams et al. (2017) combined the ANT with an incentivized flanker task in order to examine the effects of reward on behavioural measures of attentional allocation. By using a behavioural measure of alerting as a marker of phasic activity older adults showed an asymmetric response to gains and losses. Specifically, while alerting correlated with both incentive effects of gain and loss incentives in younger adults, in older adults, alerting only correlated with the effect of gain incentives. Thus, behavioural measures seem to support the idea that changes across the lifespan result in changes in the recruitment in LC-NE activity, which in turn affects how motivation modulates attention in younger and older adults. Behaviourally, age differences may exist in gain and loss motivated attention as measured by the ANT (Williams et al., 2017).

\section{Chapter 2: The Current Study}

Previous research has explored the links between incentives and alerting, and has suggested explanations of those findings based on psychological and neuroscience literatures. However, to our knowledge, no studies have examined both transient and sustained effects of 
reward on ERPs associated with an incentivized ANT with two different age groups. Hence, the present study sought to strengthen and extend previous behavioural findings (Williams et al., 2017) using electrophysiological measures. By acquiring ERPs during the incentivized ANT, this study sought to explain the underlying cognitive mechanisms by which motivation influences visual attention in younger and older adults. We were interested in identifying links between behavioural and ERP signatures associated with various aspects of attentional alerting and executive control. As mentioned earlier, given the high temporal resolution of ERP, examining the ERP components thought to be associated with the ANT and those that are influenced by the release of NE and dopamine was expected to provide useful insight into the neural mechanisms underlying age differences in gain and loss motivated attention (e.g., Williams et al., 2017).

We expected that ERPs would enable us to clarify at what stage attentional processing begins to diverge for gain and loss cues in older and younger adults. For these reasons, at the time of cue, we examined posterior N1, a negative early visual component that presents around 150-250ms after stimulus onset, and is enhanced under heightened attention (Talsma, Slagter, Nieuwenhuis, Hage, \& Kok, 2005). This component is often associated with an alerting effect. $\mathrm{CNV}$, which occurs in the time between a signal and target, and studies have provided evidence that it shows effects of both orienting and alerting (e.g., Galvao-Carmona et al., 2014; Williams et al., 2016). Then, we examined target-N1, which has also been shown to exhibit effects of alerting (e.g., Neuhaus et al., 2010; Galvao-Carmona et al., 2014). Lastly, we examined targetP3, a positive component often associated with the executive control network that is sensitive to aging (Wild-Wall, Falkenstein, \& Hohnsbein, 2008; Williams et al., 2016).

Based on prior studies, the current study was specifically concerned with the age-related differences in the incentive-based modulation of two attentional networks, which have mixed 
findings with regard to age differences: executive control and alerting. It was expected that different types of motivation would enhance attention networks differentially. We predicted an asymmetric effect of losses and gains, such that gain incentives would more strongly modulate attention as compared to loss incentives. Furthermore, using ERPs allowed us to attempt to elucidate the mechanisms by which motivation affected attention prior — and during —an individual's behavioural response. The current study also examined the interaction of two attentional networks when younger and older adults were placed into different reward-based motivational states. Similar to prior studies investigating transient and sustained effects of reward, motivational states were manipulated on a trial-by-trial basis through a mixed block/event-related design (Chiew \& Braver, 2013; Jimura et al., 2010; Williams, Kudus, Dyson, \& Spaniol, 2018).

To address the replication aspect of the study, we hypothesized that: 1) There would be a dissociation between gains and losses for older adults, such that gain effects on performance would be correlated with phasic arousal effects, as measured by a behavioural marker of phasic alerting. Extending on previous work, we also hypothesized that 2) Age differences would emerge in the incentive-based modulation of the alerting and executive control networks, and 3) The asymmetric relationship between gain and loss would present itself on ERP measures that are thought to be correlated with reward and NE release during processing of the cue (e.g., N1, $\mathrm{CNV}$ ) and/or target (N1, P3).

\subsection{Method}

Participants. Twenty-six younger adults $(M=23.13 ; S D=4.70)$ and 24 older adults $(M=71.36, S D=4.74)$ participated in the study. Younger adults were recruited through online postings as well as physical posters around Ryerson University Campus. Older adults were 
recruited from the Ryerson Senior Participant Pool. Prior to participating, potential participants took part in a phone screening (see Appendix A), which included questions about demographics (age, sex, education, English language proficiency) and health conditions that could have affected cognitive-affective function or the ability to complete study tasks (e.g., psychiatric and neurological conditions, cardiovascular disease, cancer, or sensorimotor conditions). Included participants reported normal or correct-to-normal hearing and vision, and were free of any major medical, neurological, or psychological problems. Participants had to be native speakers of English or possess native-like English language proficiency and have a minimum 12 years of education. We aimed to recruit equal numbers of men and women in both age groups, and to match average years of education of both age groups. Individuals who did not meet the inclusion criteria were thanked for their interest, but were not invited to participate in the study. After excluding participants who did not meet our criteria for task performance, or had issues with the EEG data recording, our final sample consisted of 24 younger adults and 22 older adults. Group characteristics for this sample show typical age-related differences (see Table 1). All participants received \$25 in cash in compensation for completing the study, which lasted between 2-2.5 hours, plus an additional bonus that they won during the experimental task (up to a maximum of \$30). We obtained approval for all study procedures from the Research Ethics Board of Ryerson University.

Background Measures. Prior to beginning the experiment, participants completed six background measures. This allowed us to characterize the sample and to examine potential affective and cognitive covariates of experimental measures (see Appendices B-G). The Mini Mental State Exam (MMSE; Folstein, Folstein, \& McHugh, 1975) is an 11-item questionnaire that measures cognitive functioning, with a maximum score of 30. All participants scored at least 
27, and no participants had to be excluded based on this measure. The Mill Hill Vocabulary Scale (MHV; Raven, 1982) is a 34-item measure of verbal intelligence in which participants are asked to identify synonyms using a multiple-choice format. The Digit Symbol Substitution Task (DSST; Wechsler, 1997) is a subset of the Wechsler Adult Intelligence Scale-third edition (WAIS-III), which measures perceptual-motor speed. Participants are shown 9 digit-symbol pairs, given a list of digits, and are prompted to fill in as many symbols as they can within a twominute time period. The Behavioural Inhibition/Behavioural Activation Scale (BIS/BAS; Carver and White, 1994) is used to measure dispositional traits associated with differences in sensitivity to reward and punishment. The BIS/BAS includes an inhibition scale and an activation scale, the latter of which comprises three subscales: Reward responsiveness, drive, and fun-seeking. The Positive and Negative Affect Schedule (PANAS; Watson, Clark, \& Tellegen, 1988) is a 20-item questionnaire that measures positive and negative affect. Lastly, participants completed the Depression Anxiety Stress Scales (DASS-21; Lovibond \& Lovibond, 1995), a 21-item questionnaire that measures depression, anxiety, and stress.

Design and Apparatus. A modified version of the ANT was used and administered using Presentation software (Neurobehavioural Systems; Berkeley, CA), with participants seated approximately $50 \mathrm{~cm}$ from a computer monitor. All stimuli were presented in white against a black background. Since the orienting network was not being examined, spatial and centre cues — which are traditionally used to estimate the efficiency of the orienting network — were excluded. Furthermore, neutral flankers were excluded based on prior evidence that ERPs for congruent and neutral flankers are similar (Neuhaus et al., 2010). These modifications are similar to those used in the ANT-G, which is commonly used in geriatric populations (Van Dam, 2013). After excluding these conditions, the final experimental design included the within-subjects 
factors cue (no cue, double cue) and flanker (congruent, incongruent) The task additionally featured a within-subjects incentive manipulation, which included 3 block types: gain (G), loss $(\mathrm{L})$, and neutral $(\mathrm{N})$. G and $\mathrm{L}$ blocks were referred to as incentive blocks. Within incentive blocks, incentive availability varied trial-to-trial. On incentive trials (I), ten cents was at stake. On neutral trials $(\mathrm{N})$, there were no incentives. In neutral blocks, only neutral trials were presented $(\mathrm{NN})$. Lastly, the mixed-factorial design of this task also included age group (younger, older) as a between-subjects factor. After taking into account the block- and trial-level manipulations, this design resulted in five unique trial types: Gain-incentive (GI), gain-neutral (GN), loss-incentive (LI), loss-neutral (LN), and neutral-neutral (NN).

Within each of the trial types, the four combinations of the two ANT cue conditions (e.g., no cue, double cue), and two flanker conditions (e.g., congruent or incongruent) were presented with equal frequency. This resulted in the 48 trials of each trial type $\mathrm{x}$ ANT cue $\mathrm{x}$ flanker combination. As a result of the neutral blocks having only a single trial type, neutral blocks consisted of 48 trials, whereas incentive blocks consisted of 96 . The total trial count over the course of the six experimental blocks was 480 . Two arrows flanked the target (e.g., the central arrow) on either side. The flanking arrows faced either the same (congruent) or the opposing (incongruent) direction as the central arrow. Within each condition, the central arrow pointed left or right, and the row of arrows appeared above or below the central fixation cross on $50 \%$ of the trials, respectively. On no-cue trials, no warning cue was presented, whereas on double-cue trials, two asterisks appeared on the screen above and below the central fixation point prior to the target onset. Lastly, feedback indicating whether the trial was successful (i.e., gain or nonloss) or unsuccessful (i.e., nongain or loss) was presented after the participant's response. 
Prior to beginning a block, a screen indicated whether the current block would be a neutral, gain, or loss block. At the start of each trial, an incentive cue appeared in the centre of the screen for $200 \mathrm{~ms}$, indicating whether the current trial would be an incentive trial or not (i.e., "\&" on neutral trials, and "\$" on incentive trials). Then, a fixation cross was presented for a random duration ranging between 400-1600ms. After this, the ANT cue (e.g., no cue or double cue) appeared for $100 \mathrm{~ms}$, followed by another central fixation that stayed onscreen for $400 \mathrm{~ms}$. After the time had elapsed, the target arrows appeared above or below the fixation cross and participants had up to $1,700 \mathrm{~ms}$ to respond. After a response (or when the time limit elapsed), the target disappeared and a fixation cross reappeared. Following this, a feedback screen was presented.

For gain blocks, on incentive trials, “ +0.10 ” was presented for a successful trial, whereas “+0.00" was presented for an unsuccessful trial. During loss blocks, on incentive trials, "- 0.0 " was presented for a successful trial, whereas “- 0.10 " was presented for an unsuccessful trial. Feedback for neutral trials was always presented as “\#\#\#\#\#”. The presentation of feedback was followed by another fixation cross which stayed onscreen for $600 \mathrm{~ms}$, for a total trial length of $5,400 \mathrm{~ms}$. In order for a trial to be considered successful, participants were told that they had to be both accurate, and faster than a time that would be set by the computer as it tracked their RT. However, in reality, the task adapted to the responses of the participant, such that each participant would be successful on roughly $70 \%$ of incentivized trials. The task was programmed so that individualized response time limits were uniquely set per individual. That is, the response time limit was set by computing the cumulative average RT for each correct response in an incentive trial, along with a value that was adjustable. This adjustable value resulted in a 10-ms shortened response time limit whenever the participant made a correct response while above the 
$70 \%$ success threshold, and resulted in a 10-ms increased response time limit whenever an incorrect or slow response was made while below the $70 \%$ success threshold. A schematic of the trial sequence is presented in Figure 1.

Along with end-of-trial feedback, end-of-block feedback was presented at the end of each block indicating the participant's winnings during that block. In gain blocks, participants were told how much money they had gained during the block they had just completed. In loss blocks, participants were told how much money they had avoided losing during the previous block. In neutral blocks, no block feedback was given as no incentive was at stake.

Procedure. Participants were brought into the study area where the experimenter provided an overview of the study. Prior to beginning the study, individuals were asked to complete a written consent form and to ask the experimenter any questions. Additionally, participants were told that they would receive $\$ 25$, along with a bonus they could achieve during the experimental task. After this, participants completed background measures, which were presented in the following order: MHV, DSST, DASS-21, BIS/BAS, PANAS, MMSE.

Prior to beginning the experimental task, participants received the task instructions on the computer screen and through verbal explanations by the investigator. The participants were instructed to respond to the direction (e.g., left or right) of the target arrow as quickly as possible using the marked keys on the keyboard. They pressed the "," key with their right index finger if the central arrow pointed right, and the "X" key with their left index finger if the central arrow pointed left, using a standard QWERTY keyboard. Before beginning, it was reiterated to participants that they could earn an additional monetary bonus along with their initial compensation. After receiving the task instructions, participants completed three practice blocks (1 neutral block, 1 gain block, 1 loss block), each including the various trial conditions. 
Following the practice blocks, participants were presented with six experimental blocks (480 trials total). Between blocks, participants were required to take break of at least 30s duration (at least 60 s following the $3^{\text {rd }}$ experimental block). The order of the experimental blocks was counterbalanced across participants.

Following the task and completion of the various background measures, participants were debriefed, compensated for their time, and given the bonus earned during the task (younger: $M=$ 18.50, $S D=21$; older: $M=18.50 ; S D=.18$ ), which was not significantly different for younger and older adults, $t(44)=.15, p=.88$.

ERP Acquisition and Processing. Electrical brain activity was continuously collected for offline processing using an ActiveTwo system (BioSemi; Amsterdam, Netherlands) over an array of 64 electrodes, with a band-pass filter of $208 \mathrm{~Hz}$ and a $512 \mathrm{~Hz}$ sampling rate. Recordings were acquired from $\mathrm{Ag} / \mathrm{AgCl}$ electrodes, which were connected to a cap (Cortech Solutions; Wilmington, NC) at 64 sites, according to the International 10-20 system. Six electrodes were attached externally, with two being placed on the right and left mastoids. Four electrodes were then used to record horizontal and vertical movements for both eyes by placing at the outer canthi and inferior orbits, respectively.

EEGlab (Delorme \& Makeig, 2004) and ERPLab (Lopez-Calderon \& Luck, 2014) were used to conduct off-line processing. EEG data were referenced to the average of the right and left mastoids and were resampled as $256 \mathrm{~Hz}$. High-pass $(0.1 \mathrm{~Hz}, 12 \mathrm{~dB} /$ octave) and low-pass $(30 \mathrm{~Hz}$, $24 \mathrm{~dB} /$ octave) filters were applied to the continuous data. Then, both cue and targets were epoched between $200 \mathrm{~ms}$ pre-stimulus and $1000 \mathrm{~ms}$ post-stimulus. Independent component analysis was used to correct artefacts (e.g., eye blinks, lateral eye movements). 
Behavioural Data Analysis. If a participant did not make a response for more than $10 \%$ of trials within a block, the block was excluded from further analyses. Blocks were also excluded from further analyses if a participant's accuracy was below $60 \%$ in a given condition of Trial Type $\times$ Cue $\times$ Congruency within a block. If more than one block needed to be excluded, the participant was excluded from analyses altogether. One older adult was excluded on this basis.

Accuracy and reaction time (RT), averaged for each participant and each cell of the experimental design, served as behavioural measures of interest. Additionally, inverse efficiency (IE; Townsend \& Ashby, 1983) was calculated in order to account for potential age differences in response strategies, specifically, for differences in speed-accuracy trade-off settings (LangeMalecki \& Treue, 2012; Williams et al. 2017). IE scores are calculated by dividing RT by accuracy, for each participant and each experimental condition. Lower IE scores indicate higher efficiency.

Main effects and interactions were compared across age groups and across the different experimental conditions. For each measure, a mixed-model ANOVA was carried out involving the between-subjects factors age (younger, older) and within-subjects factors of trial type (GI, GN, LI, LN, NN), ANT cue (no, double), and flanker (congruent, incongruent). For reaction time analyses, mean RT on correct responses was used, in line with previous work (Fan et al., 2002; Mahoney et al., 2010). In situations where Mauchly's assumption of sphericity was violated, the Huynh-Feldt correction was used to adjust degrees of freedom. Additionally, significant main effects and interactions were followed up using simple effects, and Benjamini-Hochberg adjusted $p$-values (Benjamini \& Hochberg, 1995) were used to account for multiple comparisons. Comparisons were considered significant using the criterion $p_{\mathrm{BH}}<.05$. The follow-up comparisons of interest were the transient, sustained, and valence effects of incentives. Thus, we 
compared GI vs. GN trials and LI vs. LN trials to examine transient effects, GN vs. NN and LN vs. NN trials to examine sustained effects, and GI vs. LI and GN vs. LN trials to investigate valence effects.

Lastly, based on prior work, correlations between incentive effects and IE scores across the alerting network were investigated (Williams et al., 2017). Both the alerting and incentive effects were calculated as difference scores, separately for gain and loss conditions to parse out potential valence effects. The alerting effect was calculated using only neutral trials in order to keep alerting effects independent of incentive effects. That is, neutral, no cue trials (i.e., $\mathrm{GN}_{\text {no cue }}$ and $\mathrm{LN}_{\text {no cue }}$ ) scores were subtracted from neutral, double cue trials (i.e., $\mathrm{GN}_{\text {double cue }}$ and $\mathrm{LN}_{\text {double }}$ cue). This resulted in two alerting effect equations: 1) $\mathrm{GN}_{\text {double cue }}-\mathrm{GN}_{\text {no cue }}$; 2) $\mathrm{LN}_{\text {double cue }}-\mathrm{LN}_{\text {no }}$ cue, for gain and loss conditions, respectively. Similarly, the incentive effect was calculated using only no-cue trials, in order to eliminate any confounds with the alerting effect. So, incentive, no cue trial scores (i.e., $\mathrm{GI}_{\text {no cue }}$ and $\mathrm{LI}_{\text {no cue }}$ ) were subtracted from neutral, no cue trials (i.e., $\mathrm{GN}_{\text {no cue }}$ and $\mathrm{LI}_{\text {no cue }}$ ). This resulted in two incentive effect equations, 1) $\mathrm{GI}_{\text {no cue }}-\mathrm{GN}_{\text {no cue }}$; 2) $\mathrm{LI}_{\text {no cue }}-$

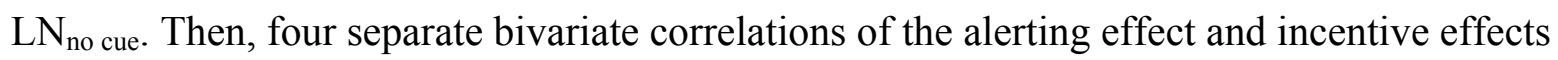
were run, separated by age group and valence type.

ERP Analysis. At the time of cue, posterior N1 and CNV were examined. Posterior N1 was examined in a time interval of $150-250 \mathrm{~ms}$ following the ANT cue. In the case of the no cue condition, we examined N1 at the time in which a cue would have occurred. We averaged this component at both parietal (P3, Pz, and P4) and occipital (O1, Oz, and O2) sites. Due to the short interval between cue and target in the ANT, we did not separate CNV into early and late components, but rather considered it as a single component from $250 \mathrm{~ms}$ after onset of the cue, to the time of the target onset (i.e., 500ms post cue-onset; Williams et al., 2016). We averaged CNV 
at frontocentral sites $(\mathrm{FCz}$ and $\mathrm{Cz})$. However, visual inspection of the timing and morphology of the CNV component suggested that it was inconsistent with previous work (e.g., Williams et al., 2016) and so further analyses were not pursued for this component.

At the time of target, posterior N1 and P3 were examined. Posterior N1 was again examined at $150-250 \mathrm{~ms}$ after the presentation of the target. As in the cue-locked analysis, N1 was examined at parietal (P3, Pz, and P4) and occipital $(\mathrm{O} 1, \mathrm{Oz}$, and $\mathrm{O} 2)$ electrodes. For our analyses of $\mathrm{P} 3$, we considered both centroparietal $(\mathrm{CPz}, \mathrm{Pz})$ and frontocentral $(\mathrm{FCz}, \mathrm{Cz})$ sites. We first determined peak latencies, using a time window of $300-800 \mathrm{~ms}$ following the presentation of the target. Based on prior research (Williams et al., 2016), it was determined that the P3 demonstrates a wider distribution in older adults, so mean amplitudes were determined over a $200 \mathrm{~ms}$ window for older adults, and a smaller $100 \mathrm{~ms}$ for younger adults. These time windows were then centred at the mean peak latencies.

\subsection{Results}

Behavioural Measures. Accuracy, reaction time (RT), and inverse efficiency (IE) were analyzed using mixed analyses of variance (ANOVA) with the between-subjects factor age (younger adults, older adults), and within-subjects factors trial type (GI, GN, LI, LN, NN), ANT cue (no, double), and flanker (congruent, incongruent). Means and standard deviations for each of these behavioural measures are displayed in Table 2. Descriptive statistics and details of the inferential statistics for each analysis can be found in Tables 3-6. Lastly, figures for behavioural measures were included to specifically highlight effects of age and trial type.

Accuracy. Accuracy was influenced by age, congruency, cue, and trial type.

Additionally, congruency interacted with age, trial type, and cue. Lastly, age interacted with trial type. On average, older adults were more accurate than younger adults. Participants were also 
more accurate in the presence of congruent flankers, and when there was no cue present. A detailed summary of the inferential statistics for these effects, separated by attentional networks, can be found in Table 3 .

An analysis of simple effects revealed that for the Congruency x Age interaction, for incongruent flankers, accuracy was significantly lower for younger adults $(M=.858, \mathrm{SD}=.08)$ than older adults $\left(M=0.918 ; \mathrm{SD}=.05 ; p_{\mathrm{BH}}<.01\right)$, indicating a reduced flanker interference effect on accuracy for older adults when compared to younger adults. In the congruent condition, younger and older adults did not show age differences in accuracy. Importantly, both age groups showed higher accuracy in the congruent $(M=0.988, S D=.04)$ compared to incongruent trials $\left(\mathrm{M}=0.88, S D=.07 ; \mathrm{p}_{\mathrm{BH}}<.01\right)$.

Further, simple effects for the Congruency x Trial Type interaction revealed that for incongruent flankers, accuracy was lower on incentive trials $(M=0.87, S D=.09)$ than on neutral trials $(M=.90, \mathrm{SD}=.07)$. However, none of the relevant transient, sustained, or valence comparisons showed any significant differences after correcting for multiple comparisons $\left(p_{\mathrm{BH}}\right.$ $>.05$ ). In addition, no significant differences emerged in the presence of congruent flankers $\left(p_{\mathrm{BH}}\right.$ $>.05)$.

Moreover, an analysis of simple effects for the Congruency x Cue interaction revealed that in the incongruent condition, participants were less accurate in the presence of a double cue $\left(p_{\mathrm{BH}}<.01 ; M=.873, \mathrm{SD}=.10\right)$ as compared to no cue $(M=.903, \mathrm{SD}=.06)$. Similar to the previous analysis, there were no significant differences on trials with congruent targets $\left(p_{\mathrm{BH}}>.05\right)$.

Finally, simple effects for the Age x Trial type interaction revealed that younger adults, but not older adults, showed modulations in accuracy based on trial type (see Figure 2). That is, younger adults showed transient effects of incentives on accuracy, such that they were less 
accurate on GI trials $\left(p_{\mathrm{BH}}<.01 ; M=.909, S D=.05\right)$ compared to GN trials $(M=.932, S D=.05)$.

Similarly, younger adults showed a decrease in accuracy in LI trials $\left(p_{\mathrm{BH}}<.01 ; M=.906, S D=.06\right)$ compared to $\mathrm{LN}$ trials $(M=.935, S D=.05)$.

Reaction time. For RT, there were significant effects of age, congruency, cue, and trial type (see Figure 3). Additionally, age interacted with cue and with congruency. Congruency further interacted with trial type and with cue. Detailed inferential statistics for the RT ANOVA can be found in Table 4.

An analysis of the Age $\mathrm{x}$ Cue interaction using simple effects revealed that for younger adults, responses were faster in the presence of a double cue $(M=507.44, S D=55.14)$ as compared to no cue $(M=535.05, S D=56.50)$. Older adults also demonstrated this pattern of being faster in the presence of a double cue $(M=712.00, S D=88.69)$, as compared to no cue $(M=726.47$, $S D=85.78)$, but to a lesser degree.

Secondly, simple effects of the Age x Congruency interaction revealed that younger adults were faster when presented with congruent flankers $(M=479.80, S D=50.22)$ as compared to incongruent flankers $(M=562.68, S D=61.76)$. This relationship was also significant in older adults, as they were faster with congruent flankers $(M=651.41 S D=76.09)$ compared to incongruent flankers $(M=787.06, S D=101.32)$.

The third interaction was a Congruency $\mathrm{x}$ Cue interaction. When presented with congruent flankers, participants were faster when there was a double cue $(M=552.4, S D=110.54)$ compared to no cue $(M=578.9, S D=104.49)$. Similarly, when presented with incongruent flankers, participants were faster in the double cue trials $(M=667.1, S D=143.18)$ when compared to the no cue trials $(M=682.6, S D=137.29)$. 
Lastly, an analysis of the Congruency x Trial Type interaction revealed that, when presented with congruent flankers, participants showed transient effects of incentives, as participants were faster in GI $(M=552.3, S D=111.04)$ compared to $\mathrm{GN}(M=571.7, S D=567.96)$ trials. This transient effect of incentives also held in the loss context, as participants were faster in LI $(M=553.0, S D=108.60)$ compared to $\operatorname{LN}(M=562.9, S D=103.07)$ trials. Furthermore, participants showed sustained effects of incentives in both and loss contexts, and performed faster in both $\mathrm{GN}(M=571.7, S D=567.96)$ and $\mathrm{LN}(M=562.9, S D=103.07)$ compared to NN $(M=588.1, S D=107.88)$ trials. Similarly, for incongruent trials, participants showed transient effects of incentives. They were faster in GI $(M=658.8, S D=144.96)$ and LI $(M=664.9$, $S D=145.22)$ when compared to neutral trials, $\mathrm{GN}(M=678.5, S D=141.31)$, and $\mathrm{LN}(M=679.8$, $S D=135.78$ ). Moreover, incentives also had a sustained effect, as participants were faster on both GN $(M=678.5, S D=141.31)$, and $\mathrm{LN}(M=679.8, S D=135.78)$ trials when compared to NN trials $(\mathrm{M}=692.331 ; S D=138.99)$. It is important to note that in both incongruent and congruent trials, participants did not show any effect of valence, such that loss and gain contexts did not differentially modulate reaction time.

Inverse Efficiency. Inverse efficiency showed main effects of age, congruency, and trial type (see Figure 4). Similar to the results for accuracy and RT, congruency interacted with trial type, and with cue. Overall, younger adults had lower IE scores than older adults, and thus were more efficient. Participants were also more efficient on trials with congruent flankers. A summary of this analysis can be found in Table 5 .

An analysis of the Congruency $\mathrm{x}$ Trial type interaction using simple effects showed that for congruent targets, incentives elicited transient effects on inverse efficiency. They were more efficient in both GI $(M=559.3, S D=115.12)$ and LI $(M=559.4, S D=110.78)$ trials when compared 
to $\mathrm{GN}(M=577.4, S D=115.90)$ and $\mathrm{LN}(M=569.3, S D=106.53)$, respectively. Participants also exhibited a sustained effect of incentives, such that they were more efficient in both GN $(M=577.4, S D=115.90)$ and $\mathrm{LN}(M=569.3, S D=106.53)$ compared to NN $(M=598.9, S D=116.08)$ trials. No significant differences emerged in trials with incongruent targets.

Lastly, an analysis of the Congruency x Cue interaction using simple effects revealed that with congruent flankers, participants were more efficient with a double cue $(M=558.3$, $\mathrm{SD}=113.19)$ than with no cue $(M=587.5, \mathrm{SD}=110.40)$. Cue did not affect IE when targets were incongruent.

Correlational Analysis. Scatterplots are shown in Figure 5, and display the correlations between the alerting and incentive effects on IE in both younger and older adults. With younger adults, the correlation was significant on gain trials, $r=.475, p=.02$, and on loss trials, $r=.455$, $p=.03$. Older adults showed a significant correlation only on loss trials, $r=.467, p=.03$, but not on gain trials, $r=.396, p=.07$.

Summary of behavioural findings. Overall, our behavioural results showed that while younger adults performed faster than older adults on average, incentives resulted in transient and sustained speed-ups of responses in both age groups. Moreover, transient—but not sustainedincentives led to decreases in accuracy, but only for younger adults, which was additionally exacerbated in the presence of incongruent targets. When the difference in speed-accuracy tradeoff response strategies of younger and older adults was controlled through their IE scores, both age groups showed sustained and transient level modulation, but only in the presence of congruent targets. Interestingly, none of these incentive-based modulations was affected by valence, as participants responded similarly to gain and loss incentives. 


\section{Cue-related ERPs}

\section{Posterior cue-N1 amplitude.}

Alerting. The ANOVA for alerting included the factors age (younger, older), trial type (GI, GN, LI, LN, NN), cue (no, double), and electrode site (parietal, occipital). This analysis resulted in main effects of age, trial type, and electrode site. Additionally, cue interacted with age, and with electrode site. A summary of the inferential statistics from this analysis is presented in Table 6. Cue-locked N1 waveforms, averaged at both occipital and parietal sites are shown in Figure 6 (younger adults) and Figure 7 (older adults). Overall, younger adults showed significantly more negative posterior cue-N1 mean amplitudes in comparison to older adults. Also, both age groups showed significantly larger N1 amplitudes at occipital sites compared to parietal sites. Cue-locked N1 waveforms for each trial type are shown in Figure 8 for younger adults and in Figure 9 for older adults. The main effect of trial type (displayed in Figure 10) revealed that the only significant comparison was the LI vs. LN comparison, indicating that participants showed a transient effect of incentives, but only in the loss context.

Simple effects of the Cue $\times$ Age interaction revealed that younger adults showed an effect of alerting, such that their mean cue-N1 amplitudes in no cue trials $(M=-.441, S D=1.01)$ was significantly less negative than in double cue trials $(M=-1.93, S D=2.20)$. No significant differences between cue types (i.e., no effect of alerting) emerged for older adults. In addition, younger adults did have significantly larger amplitudes than older adults in double cue trials $(M=-1.93, \mathrm{SD}=2.20$ vs. $\mathrm{M}=.49, \mathrm{SD}=1.22)$, but the groups did not differ when it came to no cue trials.

Then, an analysis of the Cue $\times$ Electrode site interaction showed that at occipital sites, the effect of no cue $(M=-0.25, S D=1.21)$ versus double cue $(M=-1.21, S D=2.57)$ was significant. 
However, at parietal sites, the difference between no cue $(M=-.51, S D=1.38)$ and double cue $(M=-.23, S D=2.37)$ was not significant, indicating that there was no effect of alerting parietally, but there was an effect occipitally.

\section{Summary of incentive effects on cue-locked ERP results}

Summary of incentive effects on cue-locked ERP results. Overall, our cue-locked analysis revealed that, at the cue level, participants' mean N1 amplitudes were not strongly influenced by incentives. However, participants in both age groups did show significantly more negative mean cue-N1 amplitudes when comparing LI to LN trials, indicating that they were being affected by incentives in loss contexts only, and on a trial-specific basis, rather than on a sustained level.

\section{Target-related ERPs}

\section{Posterior target-N1 amplitude.}

Alerting. The ANOVA for target-N1 included the factors age (younger, older), trial type (GI, GN, LI, LN, NN), cue (no, double), target (congruent, incongruent), and electrode site (parietal, occipital). Main effects of age, trial type, and cue emerged. These main effects were qualified by a Trial Type $\times$ Electrode Site interaction, as well as a Cue $\times$ Electrode Site interaction. The inferential statistics from this analysis are summarized in Table 7. Target-locked N1 waveforms, averaged at both occipital and parietal sites are shown in Figure 11 (younger adults) and Figure 12 (older adults). Additionally, target-locked waveforms, separately displaying each trial type are shown in Figure 13 (younger adults), and Figure 14 (older adults). Overall, mean target-N1 amplitudes were more negative in younger adults than in older adults. Further, double cues elicited more negative N1 amplitudes than no cues. The main effect of trial type indicated that participants showed a transient modulation by incentives, but only in gain blocks (shown in Figure 15). 
Simple effects were used to break down the Trial Type $\times$ Electrode Site interaction, and showed that at parietal sites, participants' mean amplitudes for GI trials $(M=-2.16, S D=3.24)$ were significantly more negative than for GN trials $(M=-1.49, S D=3.30)$, indicating that participants' mean amplitudes were modulated by incentives on a trial-by-trial basis, but only in a gain context. No relevant comparisons were significant at occipital sites. Then, simple effects used to analyze the cue $\times$ electrode site interaction revealed that at occipital sites, double cue trials resulted in significantly more negative target-N1 amplitudes $(M=-3.16, S D=3.00)$ compared to no cue trials $(M=-.02, S D=2.55)$. This pattern was also exhibited —and to a greater degree—at parietal sites, with N1 amplitudes for double cue trials $(M=-3.60, S D=3.44)$ being significantly more negative than for no cue trials $(M=0.70, S D=2.86)$.

\section{Target $P 3$ amplitude.}

The ANOVA for target P3 included the factors age (younger, older), trial type (GI, GN, LI, LN, NN), cue (no, double), congruency (congruent, incongruent), and electrode site (anterior, posterior). This analysis revealed main effects of age, cue, and electrode site. On average, younger adults had more positive P3 amplitudes compared to older adults. Mean P3 amplitudes were also more positive in the presence of no cue, and at posterior sites. These main effects were qualified by an Age x Trial Type interaction. Furthermore, electrode site interacted with trial type, cue, and congruency. Lastly, a three way interaction involving cue $\times$ congruency. A comprehensive summary of the results from inferential statistics is presented in Table 8. Targetlocked waveforms showing the effect of congruency on P3 amplitude are shown in Figure 16 (younger adults) and Figure 17 (older adults). Target-locked P3 waveforms are shown in Figures 18-19 (younger and older adults), collapsed over congruency, but separated by trial type. 
An analysis of the age $\mathrm{x}$ trial type interaction (see Figure 20) using simple effects revealed that younger adults showed significantly more positive mean P3 amplitudes in GI $(M=11.33, S D=4.05)$ related to $\mathrm{GN}(M=9.71, S D=3.59)$ trials, indicating transient incentive effects in the gain condition. Between groups, younger adults showed significantly more positive mean amplitudes than older adults, but specifically during incentive (i.e., GI and LI) trials at both anterior and posterior sites. No differences between trial types were significant for older adults.

The cue $\mathrm{x}$ electrode site interaction showed that at anterior sites, no cue trials $(M=8.49$, $S D=6.39)$ showed significantly more positive amplitudes than double cue trials $(M=6.09$, $S D=5.32$ ). This pattern also held true at posterior sites, where the amplitudes of no cue trials $(M=11.55, S D=4.86)$ were significantly more positive than those of double cue trials $(M=7.31$, $S D=5.90)$. This relationship was stronger at posterior sites compared to anterior sites.

Then, breaking down the congruency $\mathrm{x}$ electrode site interaction revealed that at posterior sites, target P3 amplitude was reduced for incongruent targets $(M=8.94, S D=5.60)$ compared to congruent targets $(M=9.93, S D=5.06)$. No significant differences emerged for anterior electrodes.

The three way interaction between Cue $\times$ Congruency $\times$ Age showed that for older adults, in double cue trials, mean P3 amplitudes were significantly lower with incongruent $(M=$ 3.46, $S D=5.64)$ compared to congruent $(M=5.50, S D=4.84)$ targets. No significant differences emerged for younger adults. Finally, after using the Benjamini-Hochberg correction for multiple comparisons, no significant pairwise comparisons emerged for the trial type $\mathrm{x}$ electrode site interaction.

\section{Summary of incentive effects on target-locked ERP results}

Target-N1 mean amplitudes were affected by trial type in both younger and older adults, and showed differences based on electrode site. Participants showed a transient effect of 
incentives, which resulted in more negative mean amplitudes in GI trials, compared to GN trials, but only at parietal sites. Target-P3 mean amplitudes also showed transient incentive-based modulation, but only in gain contexts, and only for younger adults. Specifically, target-P3 mean amplitudes were significantly more positive on GI as compared to GN trials, at both anterior and posterior sites. Finally, younger adults showed significantly more positive target-P3 amplitudes than older adults, on both GI and LI (i.e., incentive) trials.

\section{Chapter 3: Discussion}

The present study was aimed at helping to elucidate the cognitive and neural mechanisms through which motivation affects two independent attentional networks, alerting and executive control. We sought to explore the impact that motivational incentives would have on early and late attentional processes. We hypothesized that we would replicate previous findings, such that older adults would show a correlation between alerting effects and incentive effects (for gains but not for losses). This was not confirmed, although we were able to replicate results as they pertained to younger adults. We also expected that age differences would emerge in the incentive-based modulation of two attentional networks, and that these behavioural (i.e., RT, Accuracy, and IE) differences would be complemented by ERP measures that have been associated with reward (and the release of NE), at both cue and target stages. Regarding this hypothesis, we found behavioural age differences in the incentive-based modulation of the attention networks for accuracy, but not for RT, or for IE. Age differences in incentive effects also emerged in our ERP components of interest, but these did not align with our behavioural findings. That is, effects of valence were present for each of our three ERP measures of interest, which suggests that these measures may be more sensitive to motivational influences than behavioural measures. 


\subsection{Relationship Between Alerting and Incentive Effects}

In relation to the alerting network, our correlation analysis revealed that the correlation between the incentive effect and alerting effect was present for younger adults, regardless of the valence of the incentives. However, for older adults, the relationship between alerting and incentive effects only held up for loss trials, although a trend seemed to be occurring for gain trials. In previous work (Williams et al., 2017), the opposite asymmetry was found for older adults. That is, instead of older adults being more sensitive to gains - which could be explained by a positivity bias (Mather \& Carstensen, 2005)—our results lend evidence to the idea that as people age, they tend to focus more on loss prevention (e.g., Depping \& Freund, 2012; Eppinger, Hämmerer, \& Li, 2011). This is evidenced by the lack of a correlation between our alerting effect and incentive effect for older adults, but only in gain trials. However, it is worth noting that the relationship between incentives and alerting in the loss context for older adults just missed significance, and replications are needed before strong conclusions can be drawn. It is also important to mention that the correlations found in this study were not as large as those found previously. For example, the correlations in the current study were as follows: younger adult-gain trials, $r=.48$, younger adults-loss trials, $r=.46$, older adults-gain trials, $r=.40$ (not significant), older adults-loss trials, $r=.47$. Our findings resulted in correlations that were very similar in magnitude, with the non-significant finding approaching significance (i.e., $p=.07$ ). Here, there were no stark differences in the correlational findings. However, in a prior study, the correlations were: younger adult-gain version, $r=.69$, younger adults-loss trials, $r=.62$, older adults-gain trials, $r=.81$, older adults-loss trials, $r=.03$ (not significant). Importantly, the nonsignificant finding yielded a correlation with a much smaller magnitude than the significant findings. 
The differences found between these studies could be attributed to the fact that here, incentive valence was included as a within-subjects factor, rather than as a between-subjects factor. Instead of assigning participants to individual versions of the task, we had participants complete both gain and loss trial types, which allowed us to remove any variance between groups that could have contributed to larger effect sizes, but may have also contributed to the potential of carry-over effects across blocks. Although we were not able to replicate the prior finding, it is important to consider the experimental differences—other than the between/withinsubject design — that occurred between these studies. For example, Williams et al. (2017) used coloured cues to indicate an incentive trial, and did not include end-of-trial feedback. Lastly, our calculation of the alerting and incentive effects were similar but not identical to those of the prior study. Due to our manipulation of trial types, we chose to calculate our effects in a way that minimized potential confounds. As noted in our methods, as a result of minimizing potential confounds between alerting and incentive effects, we only included trials from gain and loss blocks. We also decided to exclude trials from the neutral blocks in order to keep the number of trials being compared consistent. However, this calculation led to the exclusion of all of the neutral-neutral trials, which could have had an impact on our correlational values. Several of these seemingly minor adjustments could have played a role in why our study was not able to fully replicate prior findings.

\subsection{Age Differences in Sensitivity to Gains versus Losses}

Behaviourally, we found that incentives modulated younger adults' accuracy on a trialby-trial basis, such that they were less accurate in the presence of incentives. In addition, incentives modulated RT, such that participants performed faster on incentive trials. 
Importantly, while all of our behavioural measures showed some modulation due to incentives, the valence effects were nonexistent. For accuracy, RT, and IE, neither younger nor older adults showed significant differences between gain and loss motivation. This finding runs counter to others in the literature (e.g., Samanez-Larkin et al., 2007), which often show evidence of an age-related difference in gain or loss sensitivity. On the other hand, all ERP components showed valence effects. That is, all participants were affected by loss incentives at cue-N1, and by gain incentives at target-N1. Younger adults were affected by gain incentives at target-P3 (see also Williams et al., 2018). Cue-P3, which was not examined in the current study tends to show increased amplitudes in the presence of incentives, particularly with gains (Schevernels, Bombeke, Krebs, \& Boehler, 2016). Since the modulation of target-P3 by incentive has not been thoroughly examined, it may be the case that it shows a similar pattern to that of cue-P3.

\subsection{Incentive-Based Modulation of Attention Networks}

Behaviourally, the only age difference we observed was an effect of incentives on accuracy for younger adults, but not for older adults. The presence of motivational cues resulted in younger adults moving their speed-accuracy tradeoff. This did not occur for older adults. The presence of this difference is also evidenced by the fact that younger and older adults' accuracies only significantly differed during GI and LI (i.e., incentive) trials.

IE - perhaps our most informative behavioural measure-showed transient and sustained effects of incentives, but only for congruent targets. This replicates findings from Williams et al. (2018), and hence does not provide any compelling evidence for any incentive-based modulation of inhibition due to the fact that congruent flankers do not require individuals to resolve any flanker interference, consistent with prior work (Marini et al., 2015). 
Our ERP findings add to our behavioural findings through both cue- and target-related analyses. Firstly, at the time of cue, participants showed transient incentive-based modulation, but only in loss contexts. Since posterior N1 is amplified in situations where attention is heightened (Talsma et al., 2005; Zhang et al., 2013), it is not overly surprising that this component showed modulations when a motivational cue was introduced. During loss trials, the threat of a potential loss on a trial-by-trial basis may have resulted in participants using cue information more to their benefit. However, what is unclear is why this difference only occurred for loss trials, and not gain trials. Strikingly, this pattern did not seem to hold at the level of the target, as target-N1 showed a transient effect of incentives as well, but only in gain contexts. Then, at target-P3, younger adults, but not older adults showed a transient effect of incentives, and again, only in gain contexts. The lack of modulation of target-P3 in older adults may be attributable to the age-related dopaminergic decline, as dopamine is the key neurotransmitter associated with this network (Chowdhury et al., 2013; Petersen \& Posner, 2012). Between groups, target-P3 amplitude was more positive for younger adults than older adults when incentives were present, at both anterior and posterior electrodes. This partially replicates previous findings from Williams et al. (2018), who found no incentive-based modulation of executive control in older adults, but found transient effects of incentives at target-P3 in both loss and gain contexts and younger adults.

It is important to note that while all of our behavioural measures showed some modulation due to incentive, transient effects of incentives were the most consistent, as they affected each of our behavioural measures. Interestingly, these transient effects are the only modulations that affected our ERP findings, meaning that at the electrophysiological level, participants never exhibited a sustained effect of the motivational manipulation. Taken together, 
this study presents paradoxical findings in terms of how motivation modulates attentional networks and how this relates to the valence of motivational cues. Further studies must be conducted in order to replicate and shed more light on cue- and target-related components that are well researched in terms of how they respond to incentives (e.g., cue-P3). The lack of an Age $\mathrm{x}$ Trial Type interaction at both cue-N1 and target-N1 does not lend support to the LC-NE being a key candidate neural mechanism for the alerting network being modulated by incentive across age. However, the presence of an Age $\mathrm{x}$ Trial type interaction at target-P3 is consistent with the theory of striatal dopaminergic decline with aging.

\subsection{Age differences in Attention Networks}

In addition to manipulating trial type, this study also provided the opportunity to replicate previous behavioural and ERP findings investigating age differences in the ANT. On reaction time, we found typical effects of alerting (which was larger in younger adults), as well as executive control (Williams et al., 2016). On accuracy, we found that alerting effects corresponded to decreases in accuracy and typical effects of flanker interference (Gamboz et al., 2010; Williams et al., 2016). For inverse efficiency, we did not find any compelling evidence for an effect of alerting, but did find robust flanker interference effects across ages, similar to previous studies. With regard to our ERP components, we found evidence for age differences in alerting at a cue-locked component, where younger adults showed an effect of alerting, evidenced by larger N1 amplitudes during double cue trials, but older adults did not. At target, we found an alerting effect in both groups (Neuhaus et al., 2010), but did not find differences in executive control at N1. At P3, however, we provide evidence for an effect of alerting, and an effect of executive control, particularly in older adults, as evidenced by our 3-way interaction. Importantly, we did not observe a main effect of congruency, as it has often been shown that 
incongruent flankers result in a significantly reduced P3 amplitude (Barkaszi, Takács, Czigler, \& Balázs, 2016; Neuhaus et al., 2010; Wild-Wall et al., 2008; Williams et al., 2016). However, this pattern is not always shown (e.g. Zhang et al., 2013). The contradictory nature of these findings highlights the complexity of the P3 amplitude, which can be modulated based on task difficulty, and inhibitory processes (Neuhaus et al., 2010). Overall, older adults showed reduced P3 amplitudes, similar to prior work (Kaufman et al., 2016). In line with Kaufman et al. (2016), age did not interaction with congruency, which may be explained by potentially comparable mechanisms of response inhibition that are used across the lifespan.

\subsection{Limitations and Future Directions}

There are several limitations of the current study. Firstly, the ANT was altered in order to include an incentive cue prior to the presence of target in order to inform participants whether an incentive would be at stake. Although previous studies have manipulated the ANT, the inclusion of another visual cue prior to the onset of conventional trial sequence limited our analyses and ability to compare this study to prior work. Presumably, this also resulted in a CNV waveform that was not pursued for further analyses due to its inconsistencies with previous work.

Second, our monetary manipulation was quite small. At only ten cents per potential win (or loss) this may have been able to account for the lack of modulation by trial type in several of our measures. In the future, including a high and low magnitude manipulation may result in studies being able to more carefully parse out differences in incentive value, and may result in stronger effects depending on participants' sensitivity to losses and/or gains (e.g., Rosell-Negre, 2017).

Third, we did not collect information regarding income or socioeconomic status for any participants. As a financial manipulation was used as our motivational incentive, this could have 
potentially acted as a confound as participants with a higher income or socioeconomic status may not be as motivated by our manipulation, and vice versa. In the future, it would be beneficial to account for this variable. A fourth limitation, again related to our motivational manipulation, is the age difference that exists in the processing of rewards. For example, older adults have been shown to value social rewards more than financial rewards (Sparrow \& Spaniol, 2016), and show differences in neural areas (i.e., nucleus accumbens) in response to these rewards. For example, older adults showed higher activation for social rewards, whereas younger adults showed higher activation for financial rewards (Rademacher et al., 2014). Fifth, it is worth noting that incentive blocks comprised 96 trials, whereas neutral blocks included only 48 trials. Since the incentive blocks were double the amount of time, it is conceivable that participants became fatigued. Sixth, cross-sectional research does not allow us the privilege of independently categorizing age differences as opposed to simple cohort effects. Future studies should examine these effects on a more longitudinal basis in order to make any broad conclusions about age-related changes.

Despite its limitations, the current study makes a novel contribution to the literature on motivation, attention, and aging and has also shed light on several avenues for future research to be conducted. One such avenue would be to examine ERP components that are known to show incentive-based modulation (e.g., CNV, Cue-P3, P3 latency), but which we were unable to focus on in the current design. Future studies could also examine ERP components associated with the incentive cue, as well as feedback related components, such as the feedback-related negativity (FRN; Di Rosa et al., 2017).

\subsection{Conclusion}

In addition to our main research questions, the current study also provides a breadth of information on how incentives affect—or do not affect—attentional networks, Importantly, 
transient effects of incentives seemed to be more pervasive than sustained effects, the latter of which only affected two of our six dependent variables. We also provide evidence that ERP components associated with attention networks are sensitive to incentives, and more sensitive to incentive valence than our behavioural measures. This study also highlights the utility of electrophysiological methods when examining network interactions. Our study also provides further electrophysiological evidence for age differences in attentional networks, demonstrated by the age differences in each individual component that was analyzed. To our knowledge, only four studies have examined attention networks using the ANT combined with ERP and this was the first attempt at combining the ANT with transient and sustained incentives across the lifespan. Further research must be conducted in order to replicate and expand the motivationcognitive relationships in our findings. 
Tables

Table 1

Group characteristics.

\begin{tabular}{|c|c|c|c|c|c|c|}
\hline & \multicolumn{2}{|c|}{ Younger Adults } & \multicolumn{2}{|c|}{ Older Adults } & \multirow[t]{2}{*}{$t(44)$} & \multirow[t]{2}{*}{$p$} \\
\hline & $M$ & $S D$ & $M$ & $S D$ & & \\
\hline $\mathrm{N}$ & 24 & - & 22 & - & - & - \\
\hline $\mathrm{N}$ (Female) & 14 & - & 14 & - & - & - \\
\hline Age, years & 23.13 & 4.70 & 71.36 & 4.74 & 34.64 & $<.01$ \\
\hline Age range, years & $18-33$ & - & $65-80$ & - & - & - \\
\hline Education, years & 15.71 & 1.78 & 16.48 & 3.34 & 0.96 & .34 \\
\hline MHV & 17.21 & 3.40 & 23.05 & 2.98 & 6.16 & $<.01$ \\
\hline DSST & 99.38 & 14.52 & 72.64 & 15.56 & 6.03 & $<.01$ \\
\hline MMSE & 29.54 & 0.83 & 28.59 & 3.32 & 3.57 & $<.01$ \\
\hline \multicolumn{7}{|l|}{$B I S / B A S$} \\
\hline BIS & 19.04 & 4.26 & 16.00 & 2.45 & 3.00 & $<.01$ \\
\hline Drive & 11.96 & 2.42 & 9.64 & 2.11 & 3.46 & $<.01$ \\
\hline Fun seek. & 12.29 & 2.63 & 11.18 & 1.94 & 1.62 & .11 \\
\hline Reward Resp. & 17.42 & 2.30 & 16.82 & 1.89 & 0.96 & .34 \\
\hline \multicolumn{7}{|l|}{$P A N A S$} \\
\hline Positive Aff & 31.25 & 7.71 & 34.23 & 5.71 & 1.48 & .15 \\
\hline Negative Aff & 13.25 & 6.33 & 11.27 & 1.49 & 1.43 & .16 \\
\hline \multicolumn{7}{|l|}{$D A S S-21$} \\
\hline Depression & 6.92 & 5.27 & 4.45 & 4.00 & 1.77 & .08 \\
\hline Anxiety & 5.00 & 5.53 & 4.91 & 4.17 & 0.06 & .95 \\
\hline Stress & 10.33 & 7.73 & 9.45 & 5.40 & 0.44 & .66 \\
\hline
\end{tabular}

Note. $\mathrm{MHV}=$ Mill Hill Vocabulary Scale; MMSE = Mini Mental State Exam; BIS = Behavioural Inhibition System; BAS = Behavioural Approach System; PANAS = Positive Negative Affective Schedule; DASS-21 = Depression, Anxiety, and Stress Scale. 
Table 2

Means (M) and standard deviations (SD) for behavioural data.

\begin{tabular}{|c|c|c|c|c|c|c|c|c|c|c|c|c|c|}
\hline & & & & \multicolumn{2}{|c|}{ GN } & \multicolumn{2}{|c|}{ GI } & \multicolumn{2}{|c|}{$\mathbf{L N}$} & \multicolumn{2}{|c|}{$\mathbf{L I}$} & \multicolumn{2}{|c|}{$\mathbf{N N}$} \\
\hline & & & & $M$ & $S D$ & $M$ & $S D$ & $M$ & $S D$ & $M$ & $S D$ & $\boldsymbol{M}$ & $S D$ \\
\hline \multirow[t]{8}{*}{ Accuracy } & \multirow[t]{4}{*}{ Young } & \multirow[t]{2}{*}{ No cue } & Congruent & 98.9 & 2.2 & 98.6 & 2 & 98.7 & 3.1 & 99.0 & 2.2 & 98.4 & 2.1 \\
\hline & & & Incongruent & 89.6 & 9.5 & 85.4 & 7.9 & 89.0 & 10 & 85.24 & 1.1 & 90.3 & 8.9 \\
\hline & & \multirow{2}{*}{$\begin{array}{l}\text { Double } \\
\text { cue }\end{array}$} & Congruent & 99.1 & 2.1 & 98.8 & 1.9 & 99.5 & 1.4 & 98.8 & 2.3 & 98.8 & 2.6 \\
\hline & & & Incongruent & 85.2 & 13 & 80.7 & 13 & 86.6 & 13 & 79.3 & 14 & 86.6 & 10.3 \\
\hline & \multirow[t]{4}{*}{ Old } & \multirow[t]{2}{*}{ No cue } & Congruent & 99.0 & 1.7 & 98.4 & 3.2 & 98.5 & 2.7 & 98.7 & 2.1 & 98.5 & 4 \\
\hline & & & Incongruent & 92.8 & 5.6 & 93.1 & 6.2 & 93.1 & 7 & 91.7 & 2.4 & 93.0 & 6.1 \\
\hline & & \multirow{2}{*}{$\begin{array}{c}\text { Double } \\
\text { cue }\end{array}$} & Congruent & 99.2 & 2.1 & 99.4 & 15 & 99.2 & 2 & 99.2 & 7.5 & 97.9 & 3.8 \\
\hline & & & Incongruent & 90.9 & 5.8 & 88.5 & 9.3 & 91.1 & 7.7 & 91.5 & 1.6 & 92.2 & 10 \\
\hline \multirow[t]{8}{*}{ RT (ms) } & \multirow[t]{4}{*}{ Young } & \multirow[t]{2}{*}{ No cue } & Congruent & 504 & 61 & 476 & 48 & 496 & 45 & 478 & 48 & 527 & 69 \\
\hline & & & Incongruent & 575 & 66 & 558 & 86 & 582 & 69 & 558 & 66 & 596 & 76 \\
\hline & & \multirow{2}{*}{$\begin{array}{l}\text { Double } \\
\text { cue }\end{array}$} & Congruent & 466 & 56 & 450 & 52 & 465 & 58 & 450 & 50 & 485 & 56 \\
\hline & & & Incongruent & 556 & 60 & 527 & 65 & 562 & 67 & 543 & 58 & 571 & 72 \\
\hline & \multirow[t]{4}{*}{ Old } & \multirow[t]{2}{*}{ No cue } & Congruent & 668 & 92 & 655 & 86 & 655 & 68 & 648 & 68 & 682 & 82 \\
\hline & & & Incongruent & 802 & 108 & 779 & 103 & 789 & 97 & 783 & 109 & 806 & 96 \\
\hline & & \multirow{2}{*}{$\begin{array}{l}\text { Double } \\
\text { cue }\end{array}$} & Congruent & 648 & 83 & 627 & 79 & 637 & 77 & 636 & 82 & 659 & 78 \\
\hline & & & Incongruent & 781 & 102 & 772 & 108 & 787 & 99 & 776 & 117 & 797 & 108 \\
\hline \multirow[t]{8}{*}{ IE score } & \multirow[t]{4}{*}{ Young } & \multirow[t]{2}{*}{ No cue } & Congruent & 510 & 65 & 483 & 50 & 502 & 47 & 483 & 49 & 536 & 70 \\
\hline & & & Incongruent & 647 & 87 & 655 & 80 & 658 & 88 & 660 & 74 & 662 & 80 \\
\hline & & \multirow{2}{*}{$\begin{array}{c}\text { Double } \\
\text { cue }\end{array}$} & Congruent & 471 & 59 & 456 & 53 & 467 & 58 & 455 & 46 & 491 & 56 \\
\hline & & & Incongruent & 664 & 96 & 664 & 98 & 656 & 81 & 702 & 119 & 663 & 72 \\
\hline & \multirow[t]{4}{*}{ Old } & \multirow[t]{2}{*}{ No cue } & Congruent & 675 & 96 & 667 & 103 & 665 & 73 & 657 & 78 & 695 & 107 \\
\hline & & & Incongruent & 868 & 131 & 840 & 132 & 850 & 112 & 858 & 119 & 873 & 147 \\
\hline & & \multirow{2}{*}{$\begin{array}{c}\text { Double } \\
\text { cue }\end{array}$} & Congruent & 654 & 88 & 631 & 81 & 643 & 87 & 642 & 84 & 674 & 85 \\
\hline & & & Incongruent & 863 & 132 & 880 & 140 & 870 & 133 & 850 & 115 & 877 & 166 \\
\hline
\end{tabular}


Table 3

Effects of age group and task conditions on accuracy.

\begin{tabular}{lrrrrr}
\hline & $F$ & $d f$ & & $p$ & $\eta_{\mathrm{p}}{ }^{2}$ \\
\hline Omnibus ANOVA & & & & & \\
Age & $\mathbf{6 . 7 1}$ & $\mathbf{1}$ & $\mathbf{4 4}$ & $\mathbf{0 . 0 1}$ & $\mathbf{0 . 1 3}$ \\
Trial Type & $\mathbf{4 . 4 4}$ & $\mathbf{4}$ & $\mathbf{1 7 6}$ & $<.01$ & $\mathbf{0 . 0 9}$ \\
Trial Type $\times$ Age & $\mathbf{2 . 5 7}$ & $\mathbf{4}$ & $\mathbf{1 7 6}$ & $\mathbf{0 . 0 4}$ & $\mathbf{0 . 0 6}$ \\
Cue $\times$ Congruency & $\mathbf{1 3 . 0 1}$ & $\mathbf{1}$ & $\mathbf{4 4}$ & $<.01$ & $\mathbf{0 . 2 3}$ \\
Cue $\times$ Congruency $\times$ Age & 1.30 & 1 & 44 & 0.26 & 0.03 \\
Trial Type $\times$ Cue $\times$ Congruency & 0.87 & 4 & 176 & 0.48 & 0.02 \\
Trial Type $\times$ Cue $\times$ Congruency $\times$ Age & 0.93 & 4 & 176 & 0.45 & 0.02 \\
& & & & & \\
Alerting & & & & & \\
Cue & $\mathbf{7 . 8 4}$ & $\mathbf{1}$ & $\mathbf{4 4}$ & $<.01$ & $\mathbf{0 . 1 5}$ \\
Cue $\times$ Age & 1.49 & 1 & 44 & 0.23 & 0.03 \\
Trial Type $\times$ Cue & 0.49 & 4 & 176 & 0.74 & 0.01 \\
Trial Type $\times$ Cue $\times$ Age & 0.78 & 4 & 176 & 0.54 & 0.02 \\
& & & & & \\
Executive Control & & & & & \\
Congruency & $\mathbf{2 . 3 2}$ & $\mathbf{1}$ & $\mathbf{4 4}$ & $<.01$ & $\mathbf{0 . 7 2}$ \\
Congruency $\times$ Age & $\mathbf{0 . 2 1}$ & $\mathbf{1}$ & $\mathbf{4 4}$ & $<.01$ & $\mathbf{0 . 1 9}$ \\
Trial Type $\times$ Congruency & $\mathbf{5 . 4 1}$ & $\mathbf{1}$ & $\mathbf{4 4}$ & $<.01$ & $\mathbf{0 . 1 1}$ \\
Trial Type $\times$ Congruency $\times$ Age & 1.96 & 4 & 176 & 0.10 & 0.04 \\
\hline Note Significant
\end{tabular}

Note. Significant effects $(p<.05)$ are presented in bold. 
Table 4

Effects of age group and task conditions on reaction time.

\begin{tabular}{|c|c|c|c|c|c|}
\hline & $F$ & $d f$ & & $p$ & $\eta p^{2}$ \\
\hline \multicolumn{6}{|l|}{ Omnibus ANOVA } \\
\hline Age & 86.24 & 1 & 44 & $<.01$ & 0.66 \\
\hline Trial Type & 26.41 & 2.92 & 128.67 & $<.01$ & 0.38 \\
\hline Trial Type $\times$ Age & 1.59 & 4 & 176 & 0.18 & 0.04 \\
\hline Cue $\times$ Congruency & 13.31 & 1 & 44 & $<.01$ & 0.23 \\
\hline Cue $\times$ Congruency $\times$ Age & 0.00 & 1 & 44 & 0.96 & 0 \\
\hline Trial Type $\times$ Cue $\times$ Congruency & 0.44 & 3.62 & 159.16 & 0.76 & 0.01 \\
\hline Trial Type $\times$ Cue $\times$ Congruency $\times$ Age & 2.30 & 4 & 176 & 0.61 & 0.05 \\
\hline \multicolumn{6}{|l|}{ Alerting } \\
\hline Cue & 113.20 & 1 & 44 & $<.01$ & 0.72 \\
\hline Cue $\times$ Age & 11.04 & 1 & 44 & $<.01$ & 0.20 \\
\hline Trial Type $\times$ Cue & 1.85 & 4 & 176 & 0.12 & 0.04 \\
\hline Trial Type $\times$ Cue $\times$ Age & 0.37 & 4 & 176 & 0.83 & 0.01 \\
\hline \multicolumn{6}{|l|}{ Executive Control } \\
\hline Congruency & 506.71 & 1 & 44 & $<.01$ & 0.92 \\
\hline Congruency $\times$ Age & 29.54 & 1 & 44 & $<.01$ & 0.40 \\
\hline Trial Type $\times$ Congruency & 2.87 & 4 & 176 & $\mathbf{0 . 0 3}$ & 0.06 \\
\hline Trial Type $\times$ Congruency $\times$ Age & 0.08 & 4 & 176 & 0.99 & 0.00 \\
\hline
\end{tabular}

Note. Significant effects $(p<.05)$ are presented in bold. 
Table 5

Effects of age group and task conditions on inverse efficiency.

\begin{tabular}{|c|c|c|c|c|c|}
\hline & $F$ & $d f$ & & $p$ & $\eta_{\mathrm{p}}^{2}$ \\
\hline \multicolumn{6}{|l|}{ Omnibus ANOVA } \\
\hline Age & 73.48 & 1 & 44 & $<.01$ & 0.99 \\
\hline Trial Type & 26.41 & 2.92 & 128.67 & $<.01$ & 0.11 \\
\hline Trial Type $\times$ Age & 0.627 & 4 & 176 & 0.644 & 0.04 \\
\hline Cue $\times$ Congruency & 13.31 & 1 & 44 & $<.01$ & 0.29 \\
\hline Cue $\times$ Congruency $\times$ Age & 0.56 & 1 & 44 & 0.46 & 0.01 \\
\hline Trial Type $\times$ Cue $\times$ Congruency & 0.44 & 4 & 176 & 0.78 & 0.01 \\
\hline Trial Type $\times$ Cue $\times$ Congruency $\times$ Age & 2.48 & 4 & 176 & 0.05 & 0.05 \\
\hline \multicolumn{6}{|l|}{ Alerting } \\
\hline Cue & 113.20 & 1 & 44 & 0.060 & 0.72 \\
\hline Cue $\times$ Age & 11.04 & 1 & 44 & 0.63 & 0.20 \\
\hline Trial Type $\times$ Cue & 0.60 & 3.67 & 161.33 & 0.67 & 0.01 \\
\hline Trial Type $\times$ Cue $\times$ Age & 0.97 & 4 & 176 & 0.42 & 0.02 \\
\hline \multicolumn{6}{|l|}{ Executive Control } \\
\hline Congruency & 506.71 & 1 & 44 & $<.01$ & 0.92 \\
\hline Congruency $\times$ Age & 29.54 & 1 & 44 & $<.01$ & 0.40 \\
\hline Trial Type $\times$ Congruency & 2.87 & 4 & 176 & $\mathbf{0 . 0 3}$ & 0.06 \\
\hline Trial Type $\times$ Congruency $\times$ Age & 1.60 & 4 & 176 & 0.18 & 0.08 \\
\hline
\end{tabular}

Note. Significant effects $(p<.05)$ are presented in bold. 
Table 6

Effects of age group and task conditions on cue-locked N1.

\begin{tabular}{|c|c|c|c|c|c|}
\hline & $F$ & $d f$ & & $p$ & $\eta_{\mathrm{p}}^{2}$ \\
\hline \multicolumn{6}{|l|}{ Omnibus ANOVA } \\
\hline Age & 12.14 & 1 & 44 & $<.01$ & 0.22 \\
\hline Trial Type & 3.47 & 4 & 176 & $<.01$ & 0.08 \\
\hline Trial Type $\times$ Age & 1.67 & 4 & 176 & 0.16 & 0.04 \\
\hline Electrode Site & 29.35 & 1 & 44 & $<.01$ & 0.16 \\
\hline Electrode Site $\times$ Age & 1.56 & 1 & 44 & 0.51 & 0.01 \\
\hline Trial Type $\times$ Electrode Site & 1.44 & 2.10 & 90.46 & 0.24 & 0.03 \\
\hline Trial Type $\times$ Electrode Site $\times$ Age & 0.90 & 4 & 176 & 0.90 & 0.02 \\
\hline \multicolumn{6}{|l|}{ Alerting } \\
\hline Cue & 0.98 & 1 & 44 & 0.33 & 0.02 \\
\hline Cue $\times$ Age & 11.12 & 1 & 44 & $<.01$ & 0.21 \\
\hline Trial Type $\times$ Cue & 0.51 & 3.34 & 143.61 & 0.70 & 0.01 \\
\hline Trial Type $\times$ Cue $\times$ Age & 0.35 & 4 & 176 & 0.84 & 0.01 \\
\hline Cue $\times$ Electrode Site & 19.50 & 1 & 44.0 & $<.01$ & 0.31 \\
\hline Cue $\times$ Electrode Site $\times$ Age & 1.22 & 1 & 44 & 0.28 & 0.03 \\
\hline Trial Type $\times$ Cue $\times$ Electrode Site & 0.26 & 2.34 & 100.44 & 0.80 & 0.01 \\
\hline Trial Type $\times$ Cue $\times$ Electrode Site $\times$ Age & 0.69 & 4 & 176 & 0.53 & 0.02 \\
\hline
\end{tabular}

Note. Significant effects $(p<.05)$ are presented in bold. 
Table 7

Effects of age group and task conditions on target-locked N1.

\begin{tabular}{|c|c|c|c|c|}
\hline & $F$ & $d f$ & & $p$ \\
\hline \multicolumn{5}{|l|}{ Omnibus ANOVA } \\
\hline Age & 5.66 & 1 & 44 & ( \\
\hline Trial Type & 5.69 & 3.14 & 134.87 & $<$ \\
\hline Electrode Site & 0.32 & 1 & 44 & ( \\
\hline Trial Type $\times$ Age & 2.13 & 4 & 176 & ( \\
\hline Electrode Site $\times$ Age & 1.04 & 1 & 44 & ( \\
\hline Cue $\times$ Congruency & 2.08 & 1 & 44 & ( \\
\hline Cue $\times$ Congruency $\times$ Age & 1.29 & 1 & 44 & ( \\
\hline Trial Type $\times$ Cue $\times$ Congruency & 1.47 & 4 & 176 & ( \\
\hline Trial Type $\times$ Cue $\times$ Congruency $\times$ Age & 0.30 & 4 & 176 & ( \\
\hline Trial Type $\times$ Electrode Site & 2.73 & 3.33 & 143.31 & ( \\
\hline Trial Type $\times$ Electrode Site $\times$ Age & 0.27 & 4 & 176 & 0 . \\
\hline Cue $\times$ Congruency $\times$ Electrode Site & 0.03 & 1 & 44 & ( \\
\hline Cue $\times$ Congruency $\times$ Electrode Site $\times$ Age & 0.71 & 1 & 44.00 & ( \\
\hline Trial Type $\times$ Cue $\times$ Congruency $\times$ Electrode Site & 0.49 & 2.97 & 127.50 & ( \\
\hline Trial Type $\times$ Cue $\times$ Congruency $\times$ Electrode Site $\times$ & 1.55 & & & \\
\hline Age & & 4 & 176 & ( \\
\hline \multicolumn{5}{|l|}{ Alerting } \\
\hline Cue & 108.93 & 1 & 44 & $<$ \\
\hline Cue $\times$ Age & 0.08 & 1 & 44 & ( \\
\hline Trial Type $\times$ Cue & 1.73 & 3.14 & 176 & ( \\
\hline Trial Type $\times$ Cue $\times$ Age & 0.64 & 4 & 176 & ( \\
\hline Cue $\times$ Electrode Site & 17.35 & 1 & 44 & $<$ \\
\hline Cue $\times$ Electrode Site $\times$ Age & 3.53 & 1 & 44 & ( \\
\hline Trial Type $\times$ Cue $\times$ Electrode Site & 0.38 & 3.02 & 130 & ( \\
\hline Trial Type $\times$ Cue $\times$ Electrode Site $\times$ Age & 1.58 & 4 & 176 & ( \\
\hline \multicolumn{5}{|l|}{ Executive Control } \\
\hline Congruency & 0.80 & 1 & 44 & ( \\
\hline Congruency $\times$ Age & 0.53 & 1 & 44 & ( \\
\hline Trial Type $\times$ Congruency & 0.52 & 3.41 & 146.56 & ( \\
\hline Trial Type $\times$ Congruency $\times$ Age & 0.61 & 4 & 176 & ( \\
\hline Congruency $\times$ Electrode Site & 1.04 & 1 & 44 & ( \\
\hline Congruency $\times$ Electrode Site $\times$ Age & 0.23 & 1 & 44 & ( \\
\hline Trial Type $\times$ Congruency $\times$ Electrode Site & 0.83 & 3.66 & 157.27 & ( \\
\hline Trial Type $\times$ Congruency $\times$ Electrode Site $\times$ Age & 0.50 & 4 & 176 & ( \\
\hline
\end{tabular}

Note. Significant effects $(p<.05)$ are presented in bold. 
Table 8

Effects of age group and task conditions on target-locked P3.

\begin{tabular}{|c|c|c|c|c|c|}
\hline & $F$ & $d f$ & & $p$ & $\eta_{\mathrm{p}}^{2}$ \\
\hline \multicolumn{6}{|l|}{ Omnibus ANOVA } \\
\hline Age & 0.84 & 1 & 44 & $<.01$ & 0.16 \\
\hline Trial Type & 2.41 & 3.64 & 156.62 & 0.05 & 0.05 \\
\hline Electrode Site & 28.87 & 1 & 44 & $<.01$ & 0.40 \\
\hline Trial Type $\times$ Age & 4.07 & 4 & 176 & $<.01$ & 0.09 \\
\hline Electrode Site $\times$ Age & 1.16 & 1 & 44 & 0.29 & 0.03 \\
\hline Cue $\times$ Congruency & 2.83 & 1 & 44 & 0.76 & 0.00 \\
\hline Cue $\times$ Congruency $\times$ Age & 296.65 & 1 & 44 & $<.01$ & 0.19 \\
\hline Trial Type $\times$ Cue $\times$ Congruency & 0.80 & 3.20 & 137.88 & 0.53 & 0.02 \\
\hline Trial Type $\times$ Cue $\times$ Congruency $\times$ Age & 0.31 & 4 & 176 & 0.87 & 0.01 \\
\hline Trial Type $\times$ Electrode Site & 3.31 & 3.81 & 163.61 & 0.01 & $\mathbf{0 . 0 7}$ \\
\hline Trial Type $\times$ Electrode Site $\times$ Age & 0.50 & 4 & 176 & 0.07 & 0.01 \\
\hline Cue $\times$ Congruency $\times$ Electrode Site & 2.81 & 1 & 44 & 0.10 & 0.06 \\
\hline Cue $\times$ Congruency $\times$ Electrode Site $\times$ Age & 0.05 & 1.00 & 44 & 0.83 & 0.00 \\
\hline Trial Type $\times$ Cue $\times$ Congruency $\times$ Electrode Site & 0.16 & 4 & 176 & 0.96 & 0.00 \\
\hline Trial Type $\times$ Cue $\times$ Congruency $\times$ Electrode Site $\times$ & 3.34 & & & & \\
\hline Age & & 4 & 176.0 & 0.04 & 0.06 \\
\hline \multicolumn{6}{|l|}{ Alerting } \\
\hline Cue & 46.09 & 1 & 44 & $<.01$ & 0.52 \\
\hline Cue $\times$ Age & 0.29 & 1 & 44 & 0.59 & 0.01 \\
\hline Trial Type $\times$ Cue & 1.02 & 2.93 & 126 & 0.40 & 0.02 \\
\hline Trial Type $\times$ Cue $\times$ Age & 1.41 & 4 & 176 & 0.23 & 0.03 \\
\hline Cue $\times$ Electrode Site & 34.47 & 1 & 44 & $<.01$ & 0.45 \\
\hline Cue $\times$ Electrode Site $\times$ Age & 0.00 & 1 & 44 & 0.96 & 0.00 \\
\hline Trial Type $\times$ Cue $\times$ Electrode Site & 0.69 & 4 & 176 & 0.60 & 0.02 \\
\hline Trial Type $\times$ Cue $\times$ Electrode Site $\times$ Age & 0.92 & 4 & 176 & 0.46 & 0.02 \\
\hline \multicolumn{6}{|l|}{ Executive Control } \\
\hline Congruency & 1.03 & 1 & 44 & 0.32 & 0.02 \\
\hline Congruency $\times$ Age & 2.78 & 1 & 44 & 0.10 & 0.06 \\
\hline Trial Type $\times$ Congruency & 0.13 & 3.56 & 153.02 & 0.97 & 0.00 \\
\hline Trial Type $\times$ Congruency $\times$ Age & 1.44 & 4 & 176 & 0.22 & 0.03 \\
\hline Congruency $\times$ Electrode Site & 23.32 & 1 & 44 & $<.01$ & 0.35 \\
\hline Congruency $\times$ Electrode Site $\times$ Age & 0.71 & 1 & 44 & 0.41 & 0.02 \\
\hline Trial Type $\times$ Congruency $\times$ Electrode Site & 2.06 & 4 & 176 & 0.09 & 0.05 \\
\hline Trial Type $\times$ Congruency $\times$ Electrode Site $\times$ Age & 2.38 & 4 & 176 & 0.05 & 0.05 \\
\hline
\end{tabular}

Note. Significant effects $(p<.05)$ are presented in bold. 


\section{Figures}

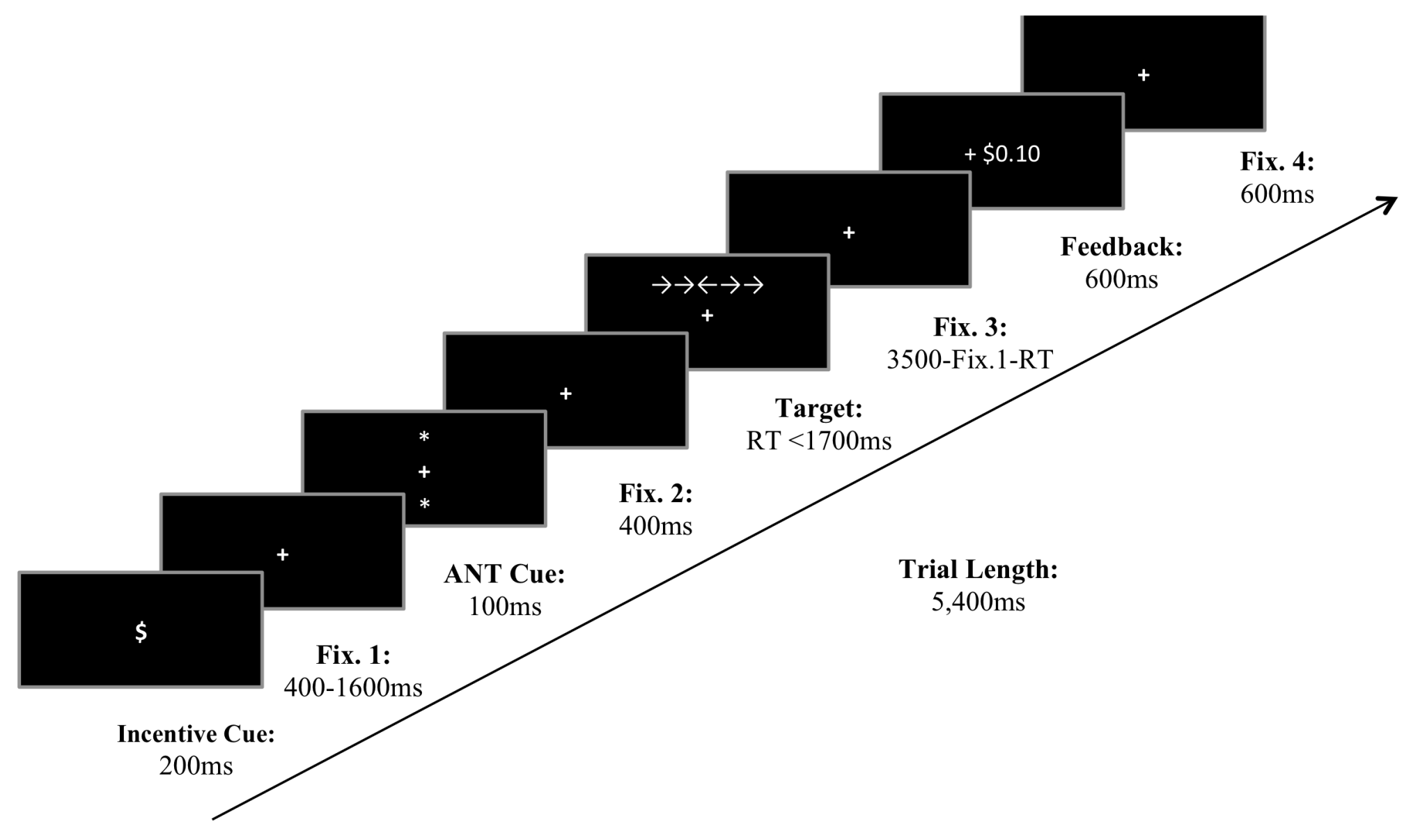

Figure 1. Incentivized ANT. Represented is a single gain-incentive (GI) trial with positive feedback. 


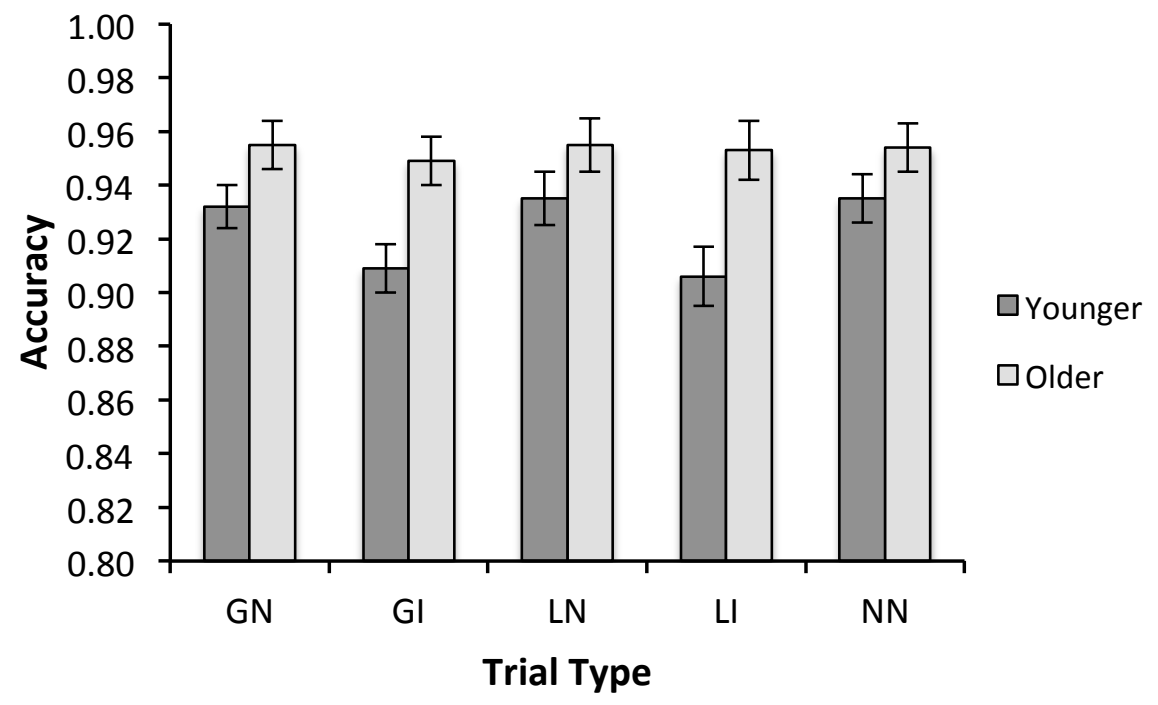

Figure 2. Accuracy for younger and older adults. GN=gain-neutral trials; GI=gainincentive trials; $\mathrm{LN}=$ loss-neutral trials; $\mathrm{LI}=$ loss-incentive trials; $\mathrm{NN}=$ neutral-neutral trials. 


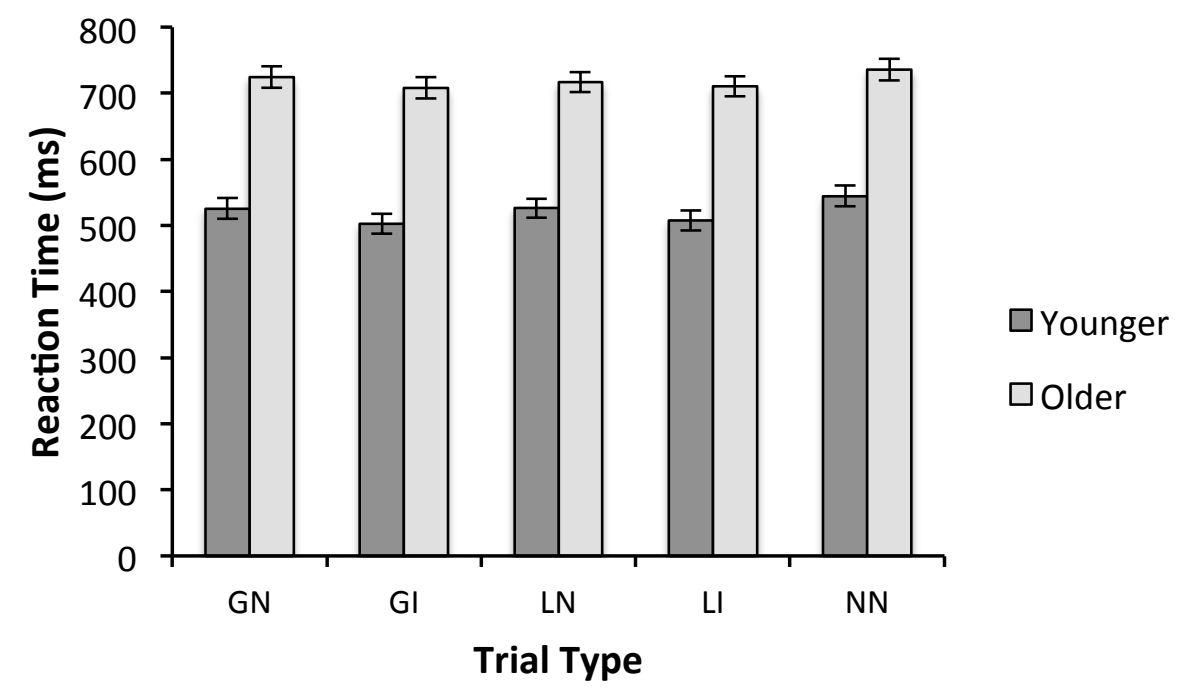

Figure 3. Mean reaction time for correct responses, for both younger and older adults. GN=gain-neutral trials; GI=gain-incentive trials; $\mathrm{LN}=$ loss-neutral trials; LI=lossincentive trials; $\mathrm{NN}=$ neutral-neutral trials. 


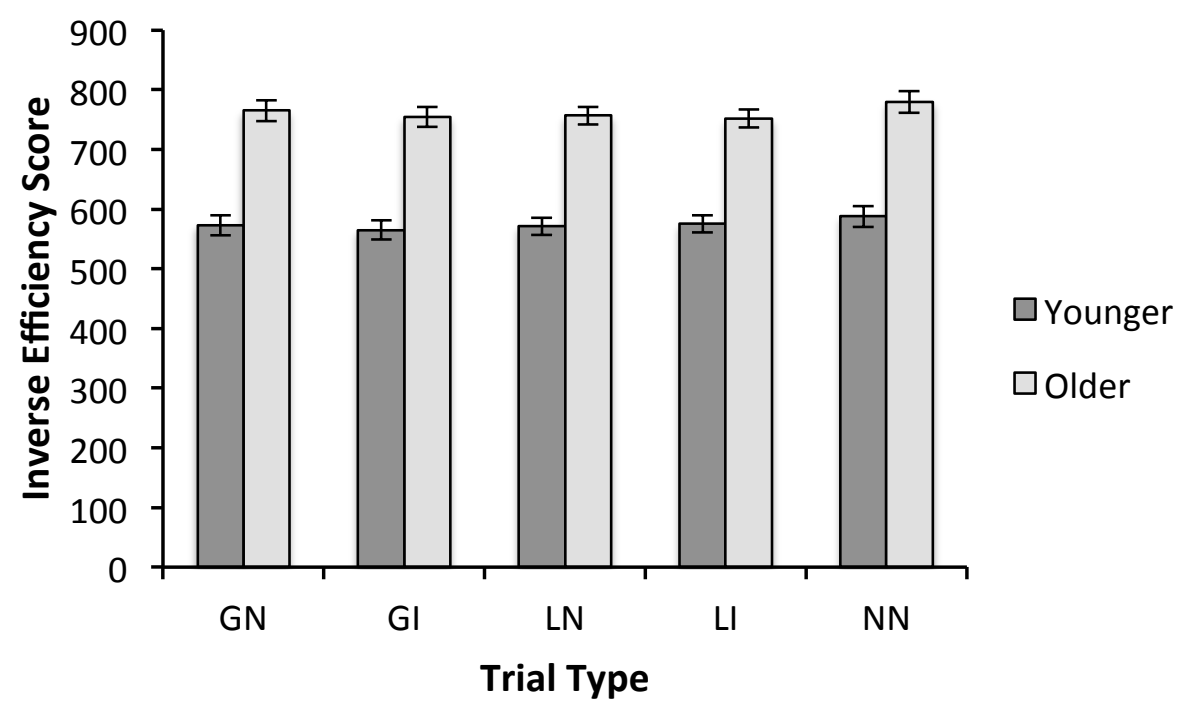

Figure 4. Inverse efficiency for younger and older adults. GN=gain-neutral trials;

GI=gain-incentive trials; LN=loss-neutral trials; $\mathrm{LI}=$ loss-incentive trials; $\mathrm{NN}=$ neutralneutral trials. 

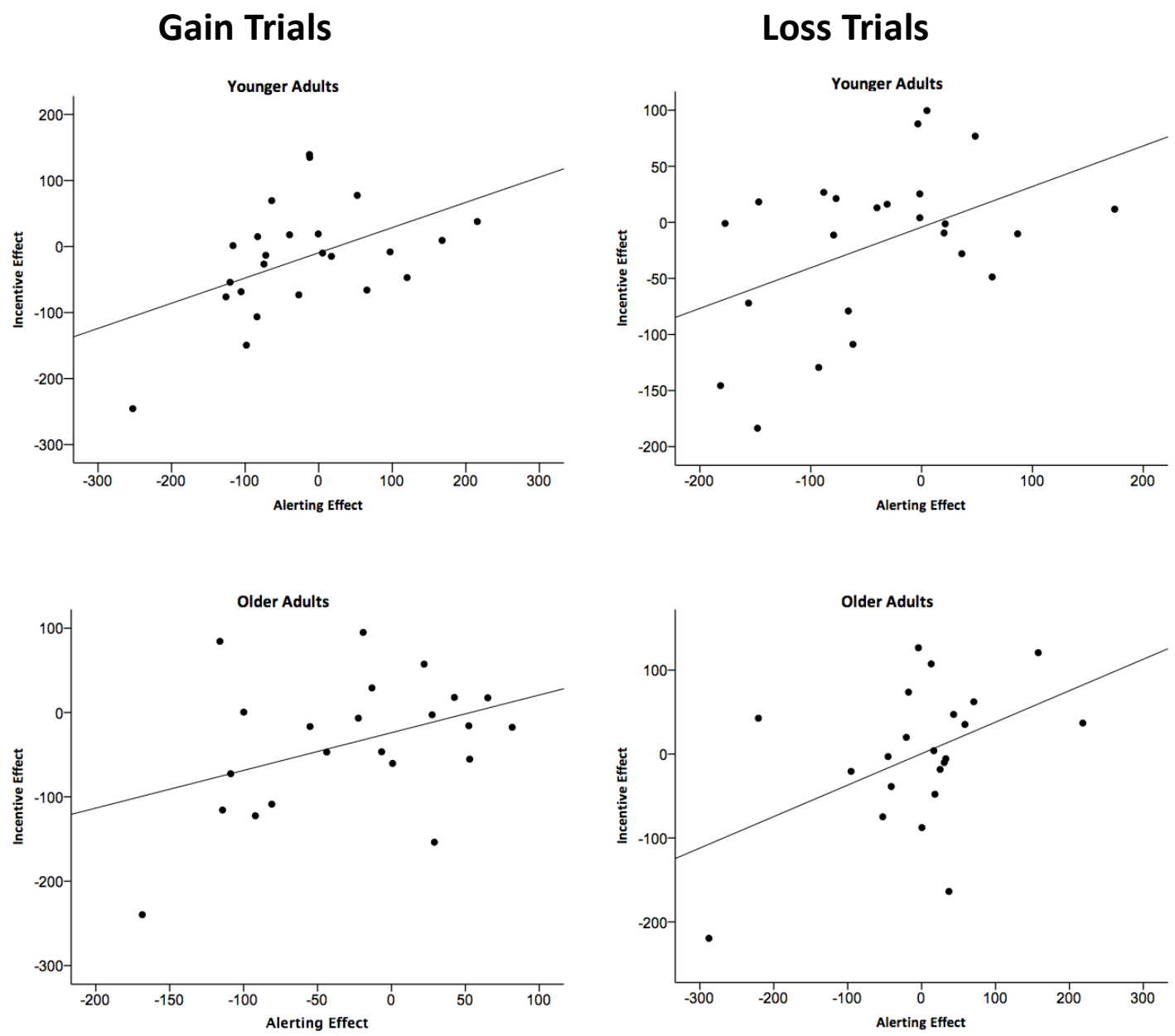

Figure 5. Relationship between incentive effects and alerting effects for participants in each age group, separated by gain and loss trials. Younger adults pictured on the top, and older adults pictured on the bottom. For younger adults, the correlation was significant on gain trials, $r=.475, p=.02$, and on loss trials, $r=.455, p=.03$. Older adults showed a significant correlation only on loss trials, $r=.467, p=.03$, but not on gain trials, $r=.396$, $p=.07$ 

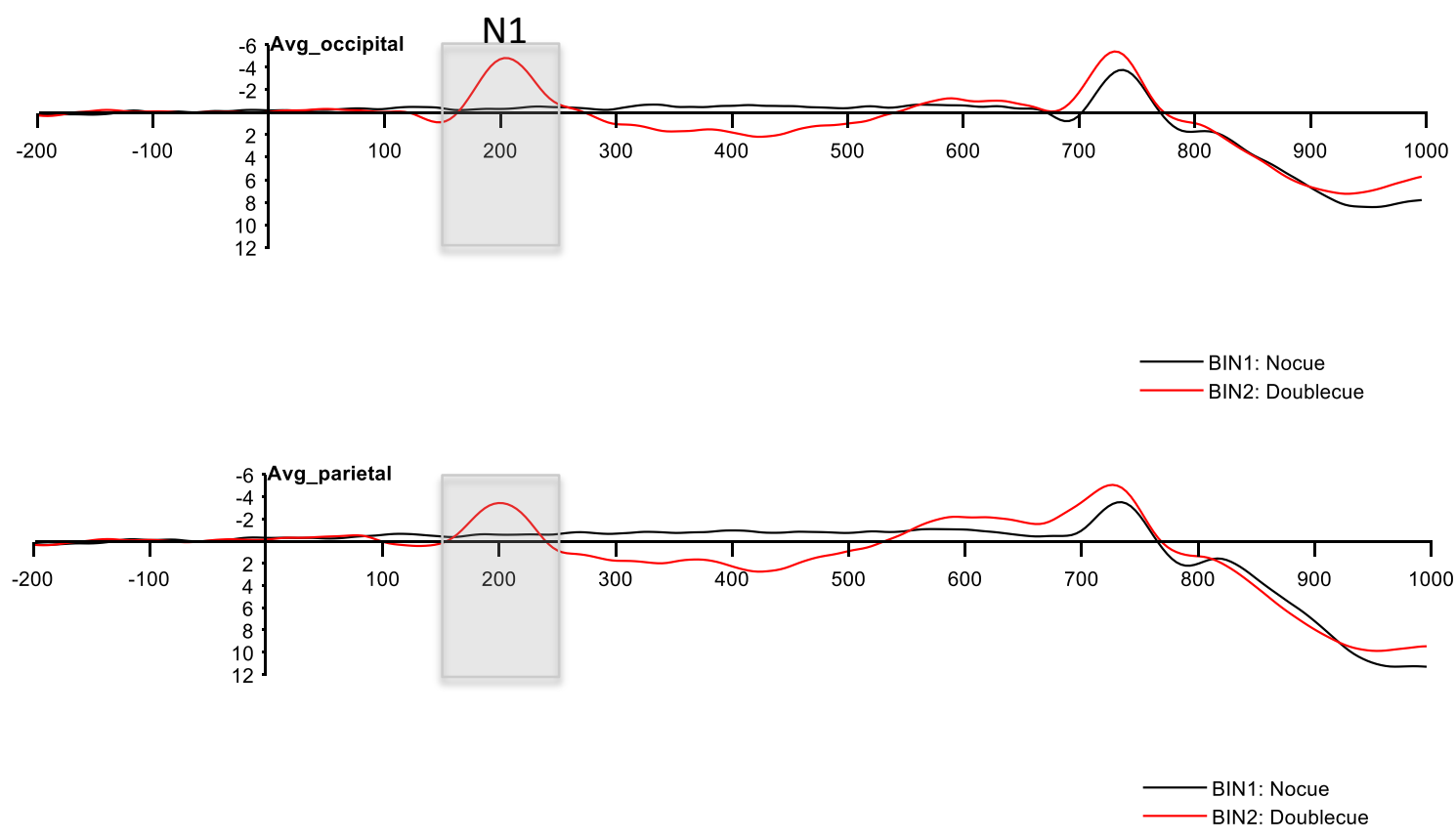

Figure 6. Averaged cue-locked N1 ERP waves at occipital (top; O1, Oz, O2) and parietal (bottom; P3, Pz, P4) electrodes for younger adults. Cue onset occurs at $0 \mathrm{~ms}$. 


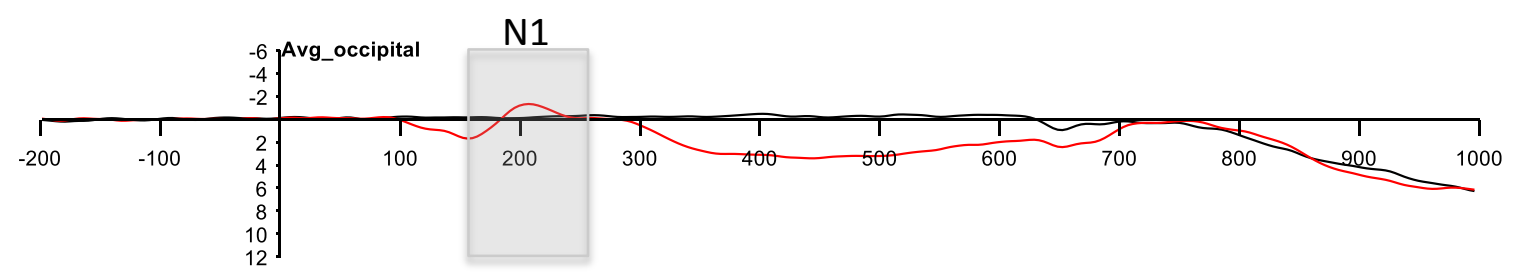

- BIN1: Nocue

BIN2: Doublecue

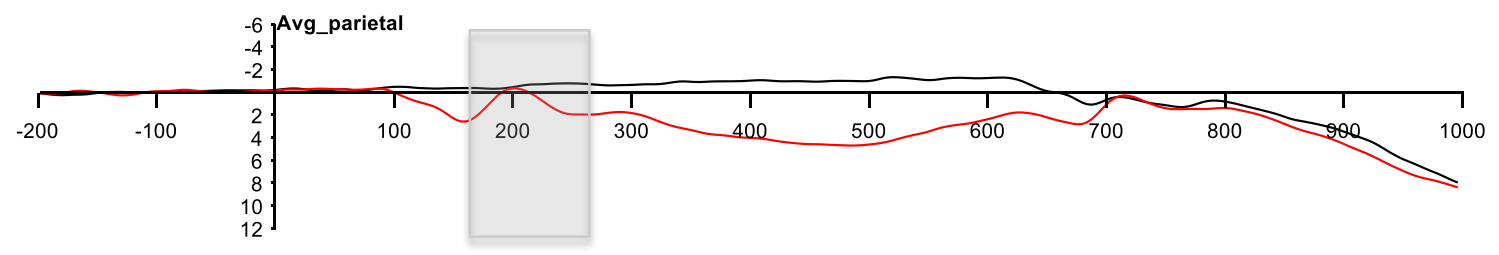

Figure 7. Averaged cue-locked ERP waves at occipital (top; O1, Oz, O2) and parietal (bottom; P3, Pz, P4) electrodes for older adults. Cue onset occurs at 0 ms. 

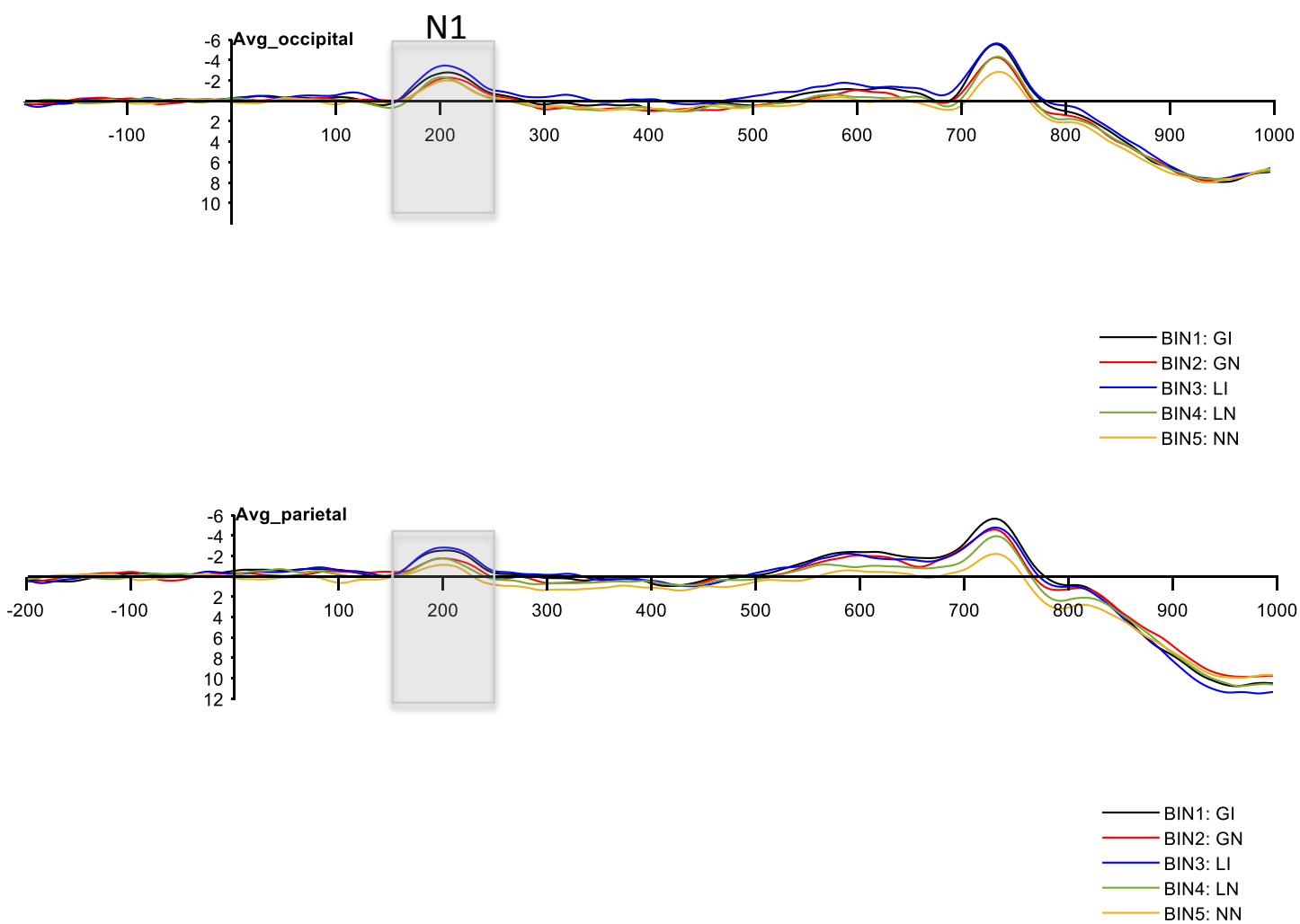

Figure 8. Cue-locked N1 ERP waves at occipital (top; O1, Oz, O2) and parietal (bottom;

$\mathrm{P} 3, \mathrm{Pz}, \mathrm{P} 4$ ) for younger adults. Cue onset occurs at $0 \mathrm{~ms}$. GN=gain-neutral trials;

GI=gain-incentive trials; $\mathrm{LI}=$ loss-incentive trials; $\mathrm{LN}=$ loss-neutral trials; $\mathrm{NN}=$ neutralneutral trials. 

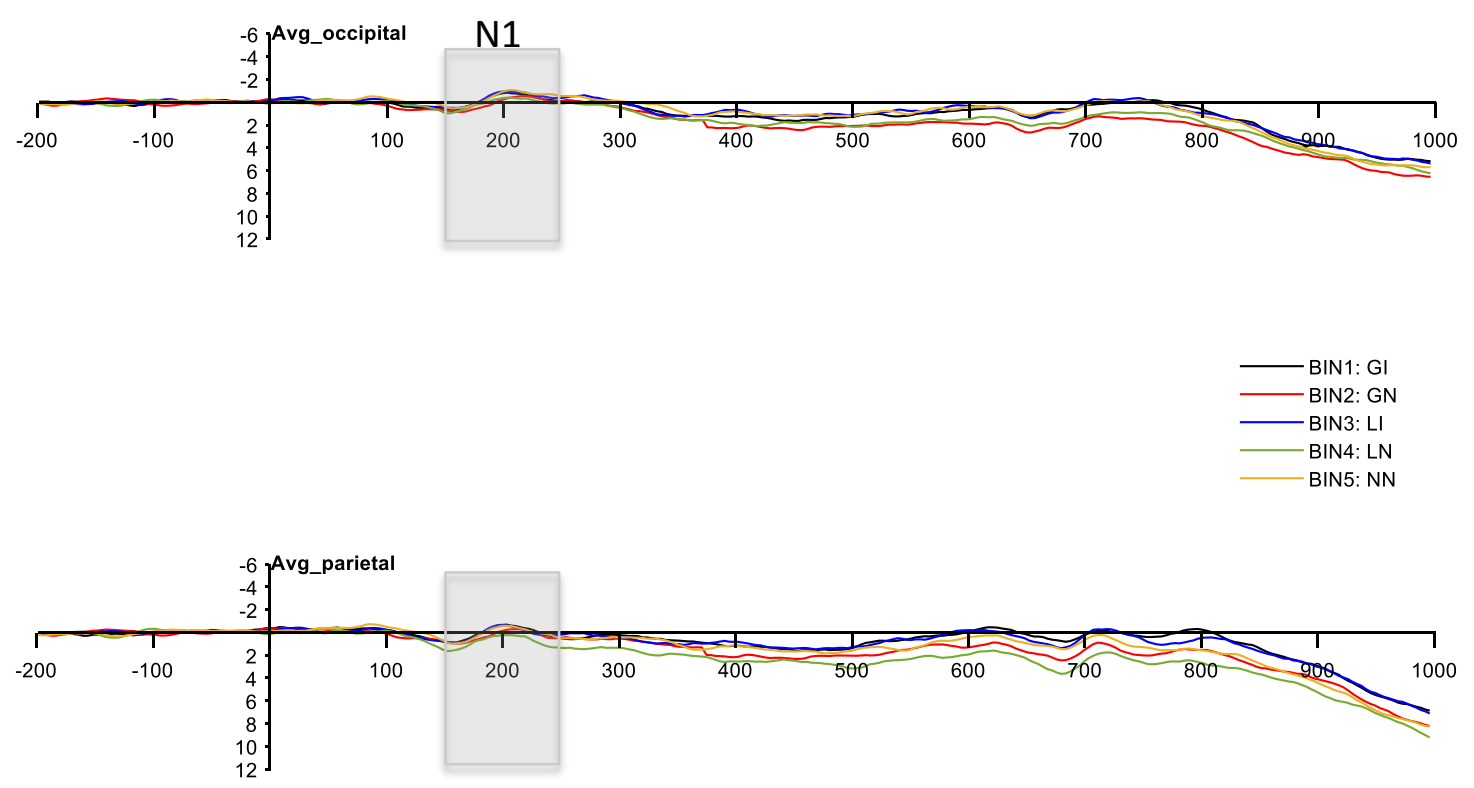

Figure 9. Cue-locked N1 ERP waves at occipital (top; O1, Oz, O2) and parietal (bottom; P3, Pz, P4) for older adults. Cue onset occurs at 0 ms. GN=gain-neutral trials; GI=gainincentive trials; $\mathrm{LI}=$ loss-incentive trials; $\mathrm{LN}=$ loss-neutral trials; $\mathrm{NN}=$ neutral-neutral trials. 


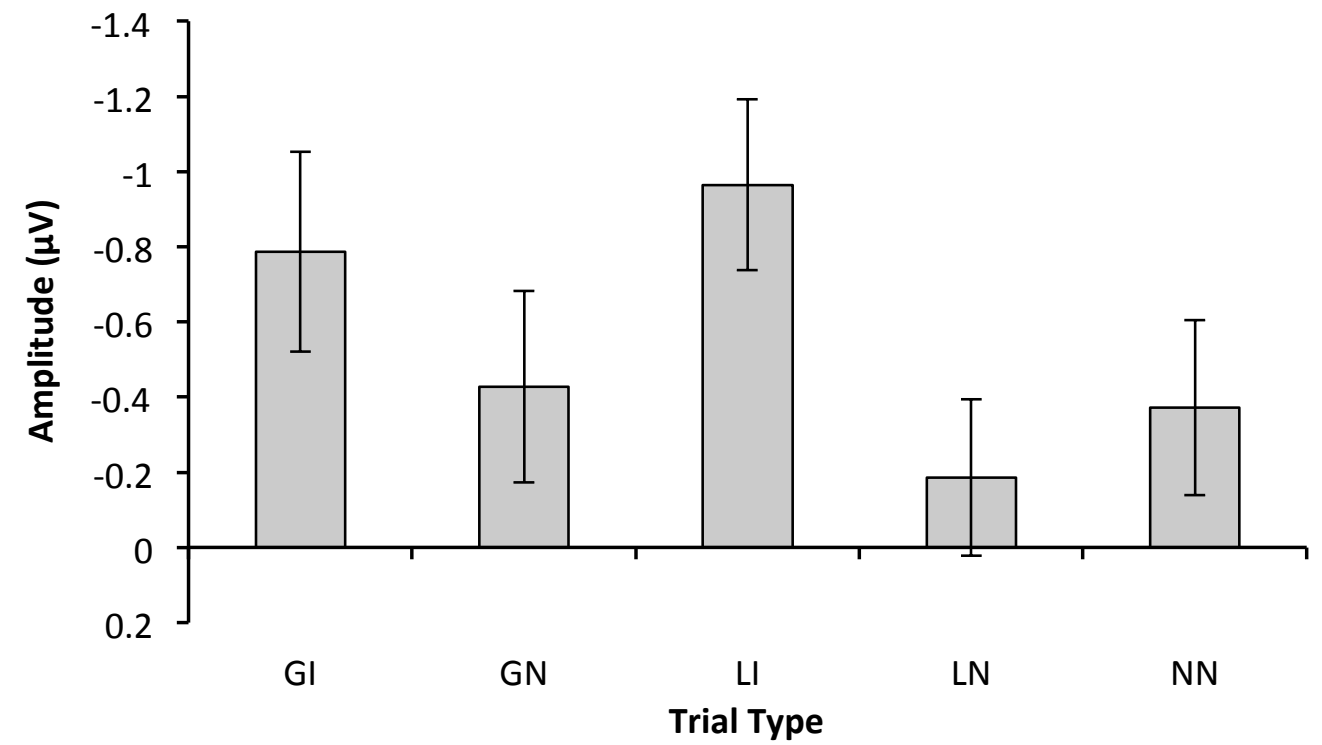

Figure 10. Mean cue-N1 amplitudes collapsed across age groups. GI=gain-incentive trials; GN=gain-neural trials; $\mathrm{LI}=$ loss-incentive trials; $\mathrm{LN}=$ loss-neutral trials; $\mathrm{NN}=$ neutral-neutral trials. 

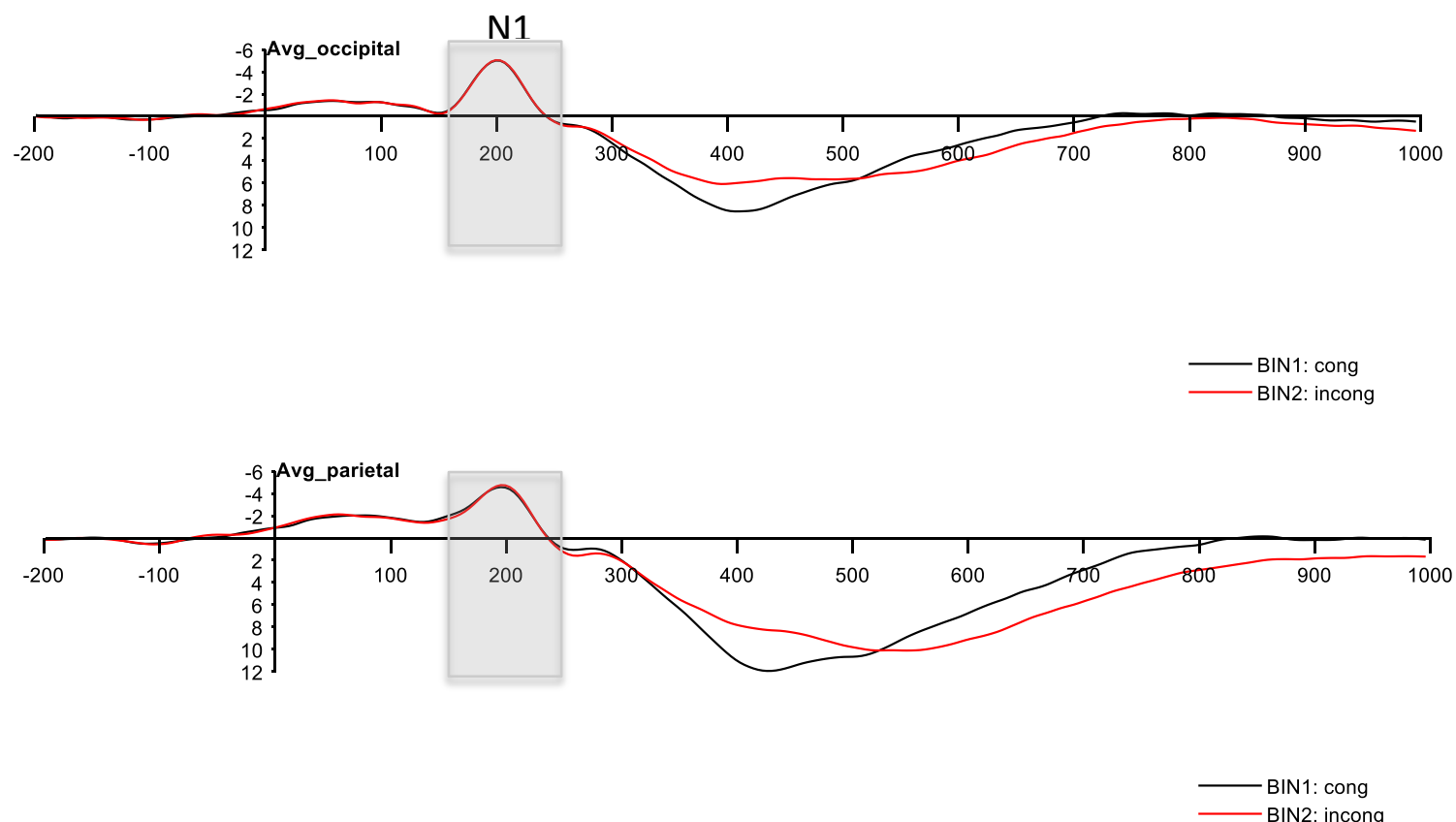

Figure 11. Averaged target-locked N1 ERP waves at occipital (top; O1, Oz, O2) and parietal (bottom; P3, Pz, P4) electrodes for younger adults, separately for congruent and incongruent targets. Target onset occurs at $0 \mathrm{~ms}$. 

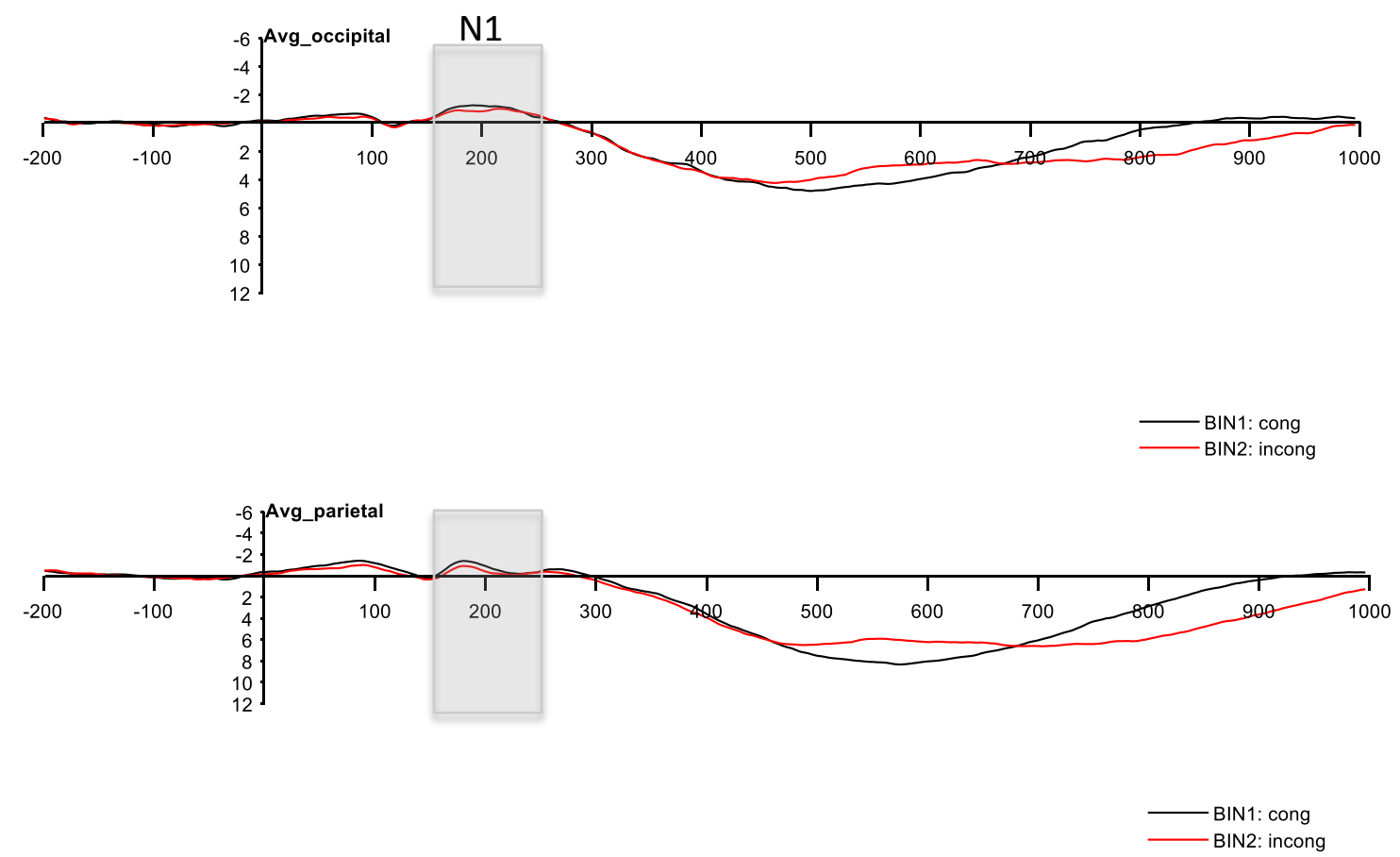

Figure 12. Averaged target-locked N1 ERP waves at occipital (top; O1, Oz, O2) and parietal (bottom; P3, Pz, P4) electrodes for older adults, separately for congruent and incongruent targets. Target onset occurs at $0 \mathrm{~ms}$. 

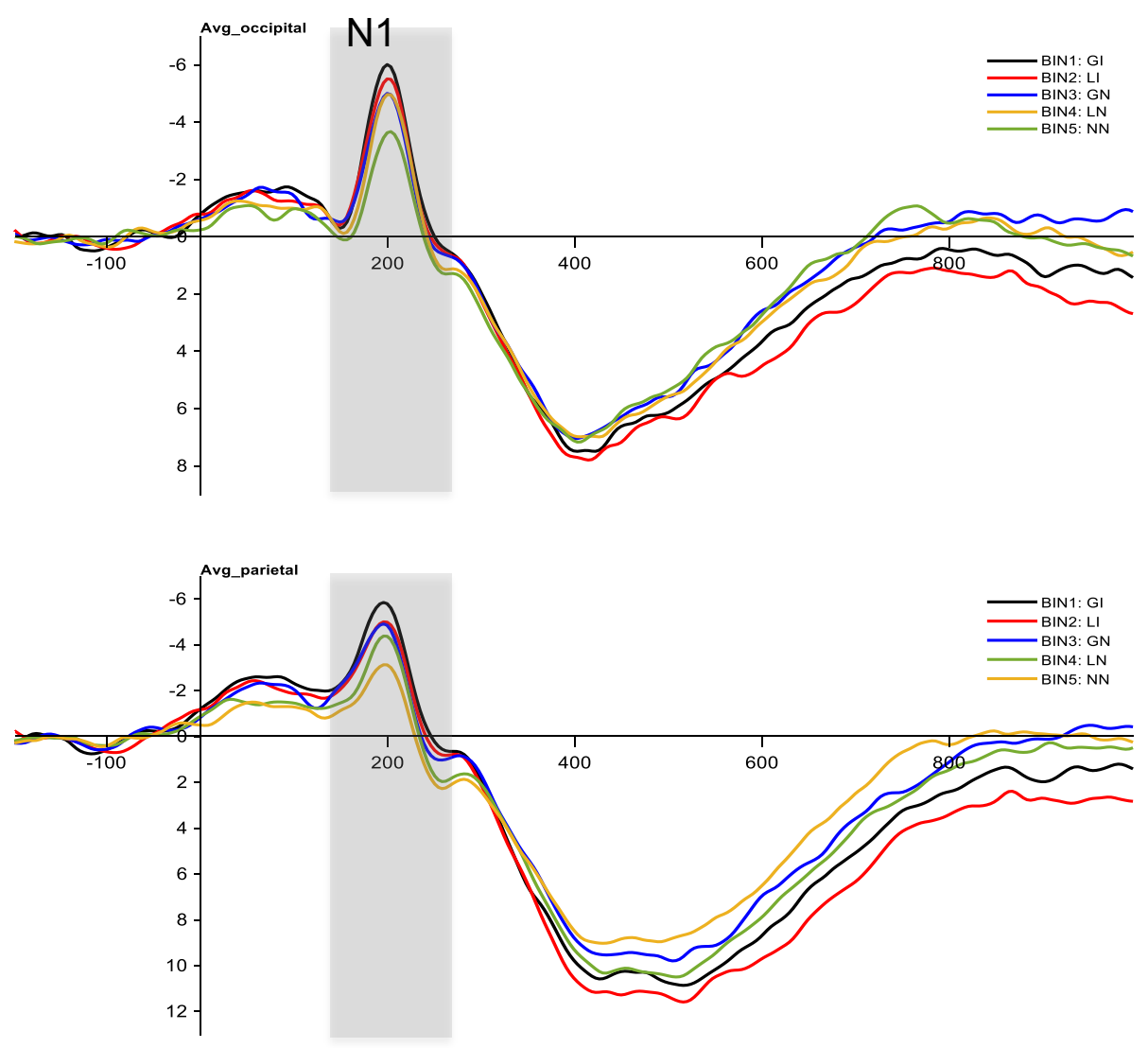

Figure 13. Target-locked ERP waves at posterior electrodes for younger adults, shown separately for the 4 trial types. Target onset occurs at $0 \mathrm{~ms}$. GN=gain-neutral trials; GI=gain-incentive trials; $\mathrm{LI}=$ loss-incentive trials; $\mathrm{LN}=$ loss-neutral trials; $\mathrm{NN}=$ neutralneutral trials. 

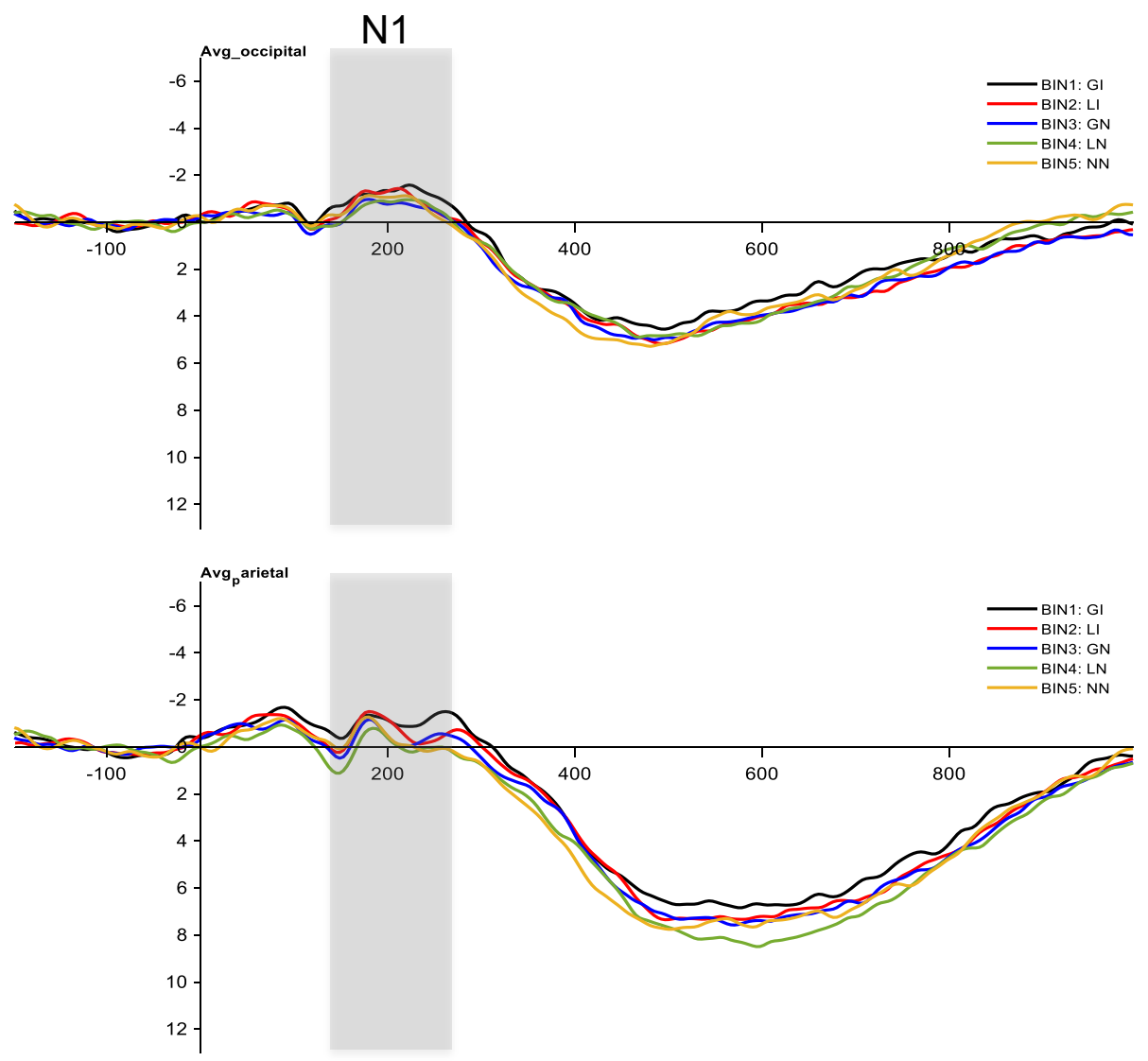

Figure 14. Target-locked ERP waves at posterior electrodes for older adults, shown separately for the 4 trial types. Target onset occurs at $0 \mathrm{~ms}$. GN=gain-neutral trials; $\mathrm{GI}=$ gain-incentive trials; $\mathrm{LI}=$ loss-incentive trials; $\mathrm{LN}=$ loss-neutral trials; $\mathrm{NN}=$ neutralneutral trials. 


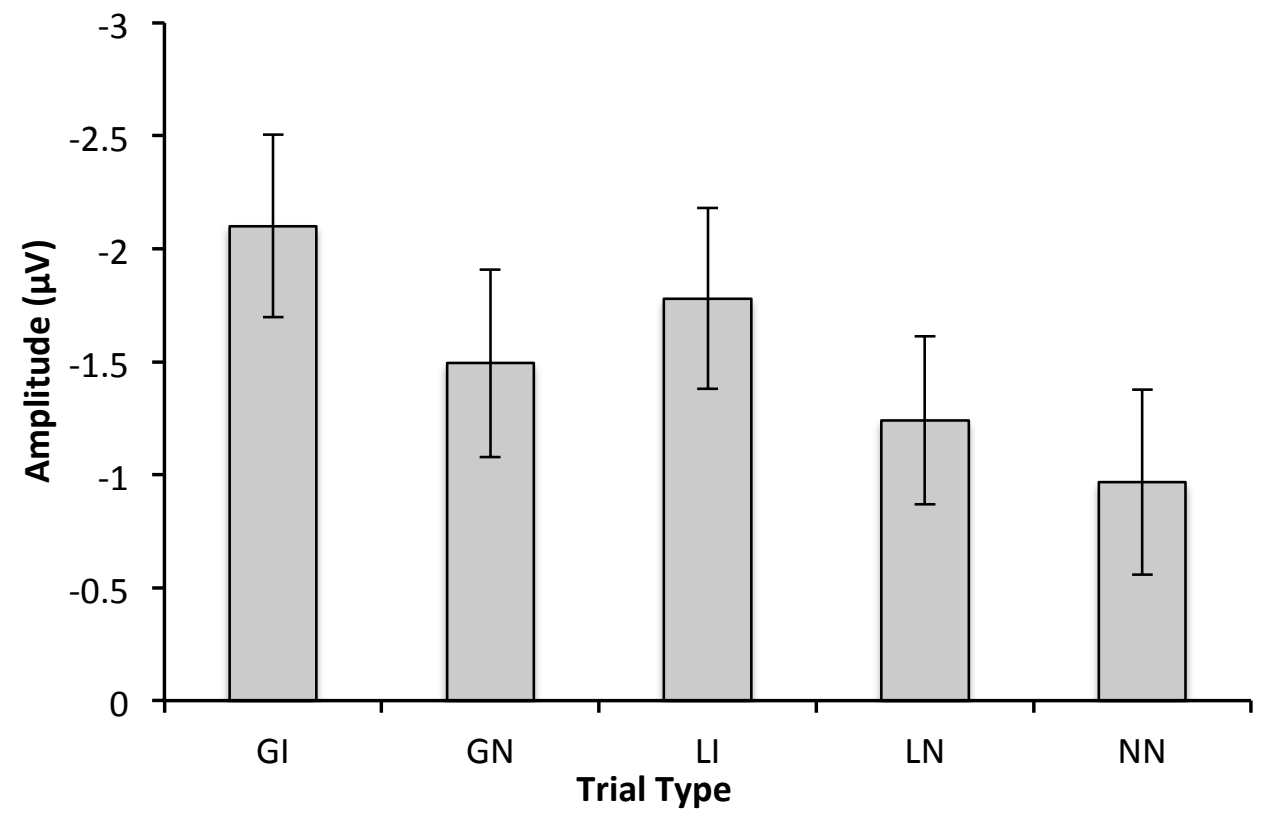

Figure 15. Mean target-N1 amplitudes for all participants. GI=gain-incentive trials; GN=gain-neutral trials; LI=loss-incentive trials; $\mathrm{LN}=$ loss-neutral trials; $\mathrm{NN}=$ neutralneutral trials. 

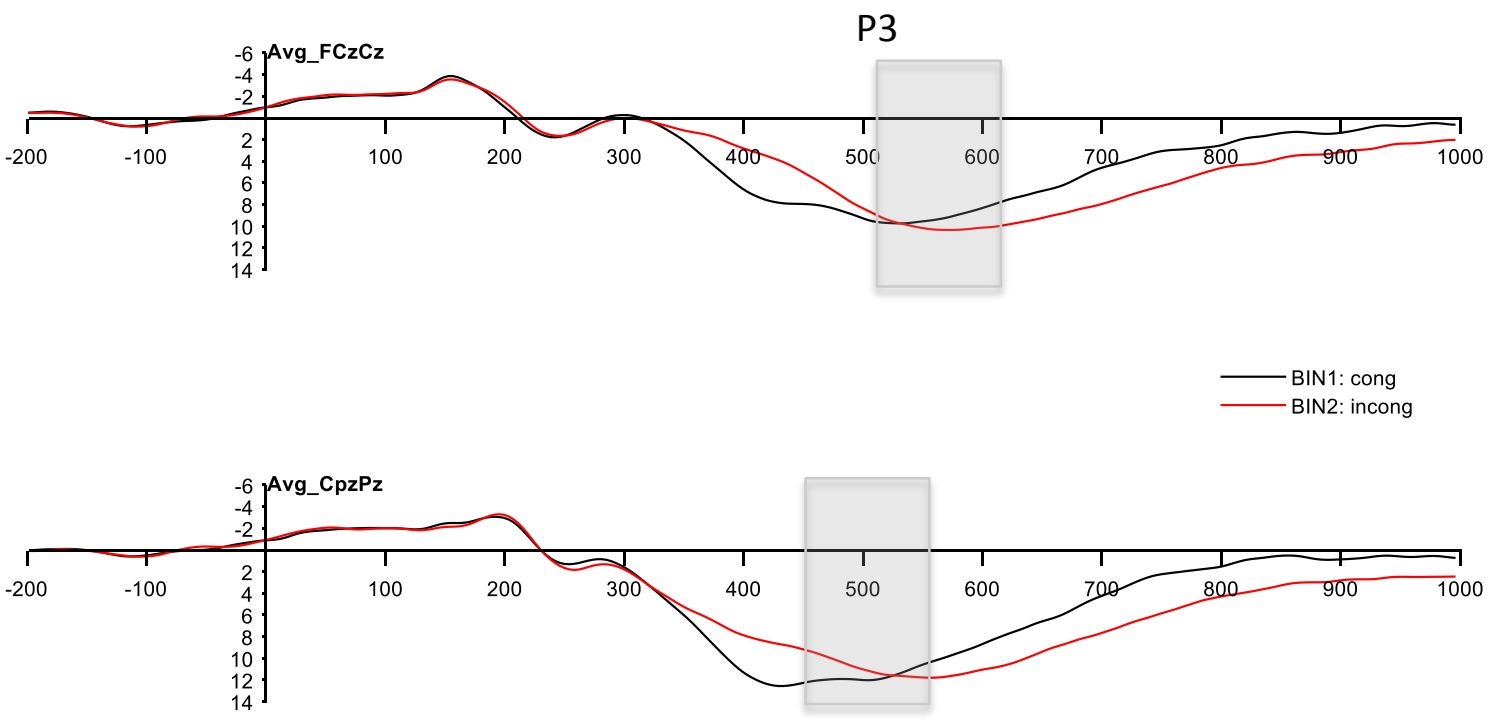

Figure 16. Averaged target-locked P3 ERP waves at frontocentral (top; FCz, Cz) and centroparietal (bottom; $\mathrm{CPz}, \mathrm{Pz}$ ) electrodes for younger adults, shown separately for congruent and incongruent targets. Target onset occurs at $0 \mathrm{~ms}$. 

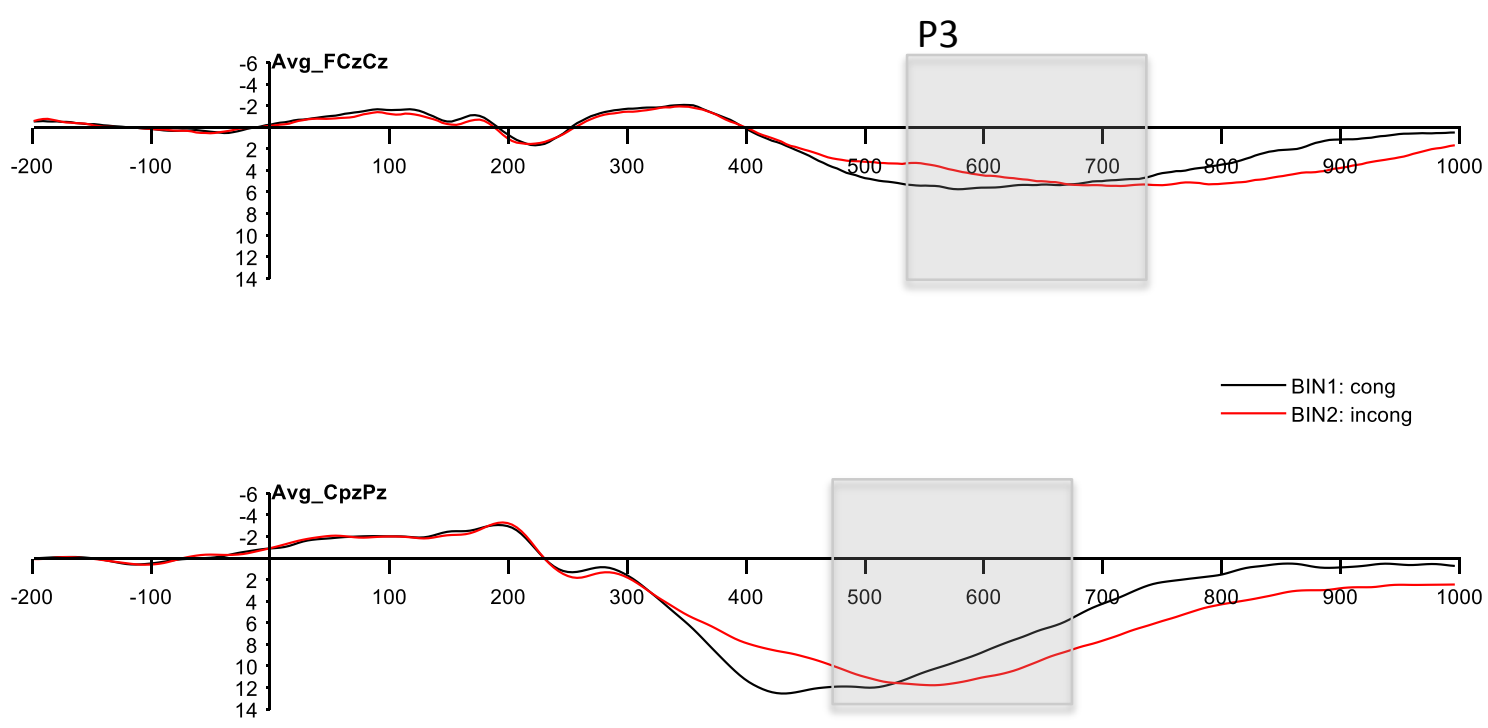

BIN1: cong

Figure 17. Averaged target-locked ERP waves at frontocentral (top; $\mathrm{FCz}, \mathrm{Cz}$ ) and centroparietal (bottom; $\mathrm{CPz}, \mathrm{Pz}$ ) electrodes for older adults, shown separately for congruent and incongruent targets. Target onset occurs at $0 \mathrm{~ms}$. 

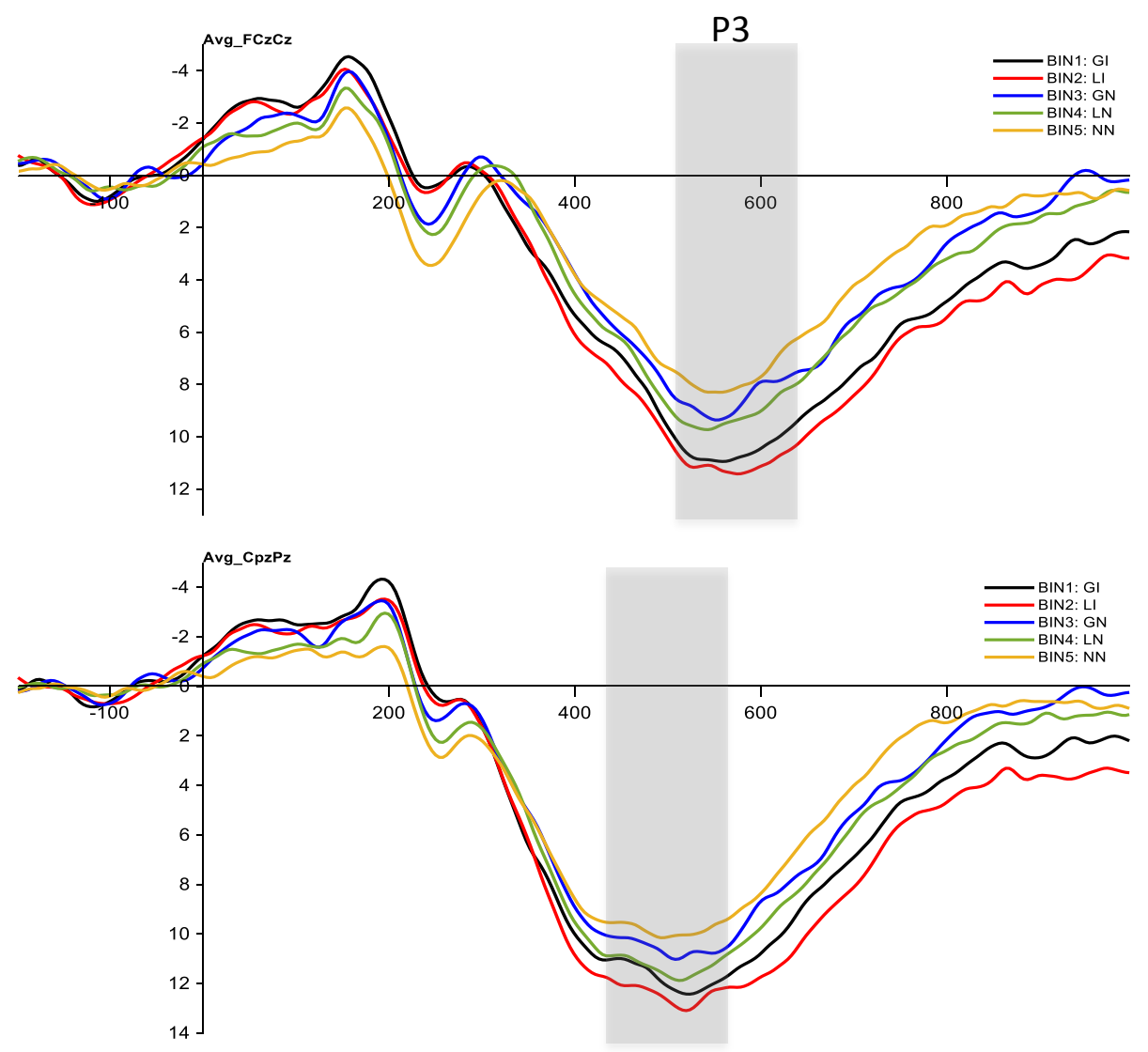

Figure 18. Target-locked ERP waves at fronto-central and centro-parietal electrodes for younger adults, shown separately for the 4 trial types. Target onset occurs at $0 \mathrm{~ms}$. GN=gain-neutral trials; GI=gain-incentive trials; LI=loss-incentive trials; LN=lossneutral trials; $\mathrm{NN}=$ neutral-neutral trials. 


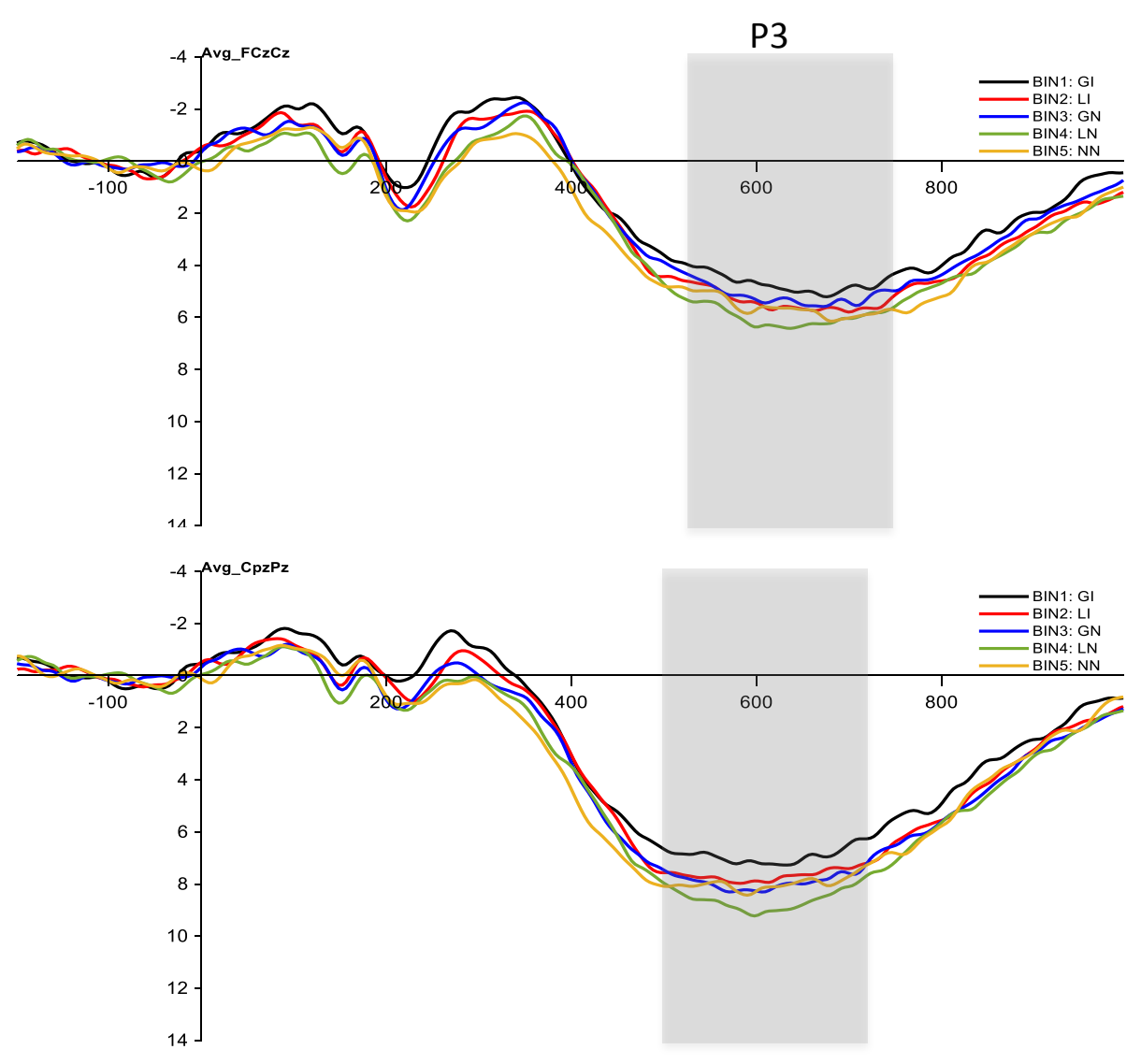

Figure 19. Target-locked ERP waves at fronto-central and centro-parietal electrodes for older adults, shown separately for the 4 trial types. Target onset occurs at $0 \mathrm{~ms}$. GN=gainneutral trials; GI=gain-incentive trials; $\mathrm{LI}=$ loss-incentive trials; $\mathrm{LN}=$ loss-neutral trials; $\mathrm{NN}=$ neutral-neutral trials. 


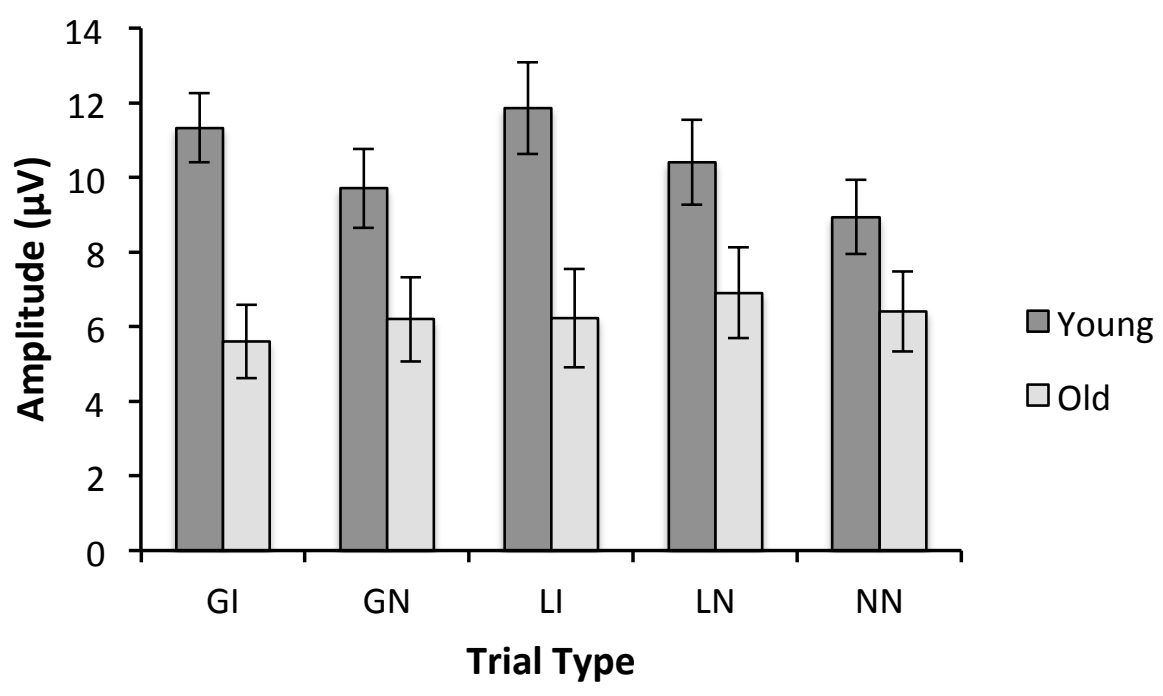

Figure 20. Mean target-P3 amplitudes for younger and older adults. GI=gain-incentive trials; GN=gain-neutral trials; $\mathrm{LI}=$ loss-incentive trials; $\mathrm{LN}=$ loss-neutral trials; $\mathrm{NN}=$ neutral-neutral trials. 


\section{Appendices}

\section{Appendix A}

\section{SCHEDULED TEST DATE:}

AT

STUDY:

\section{DEMOGRAPHICS / PHONE SCREENING}

\begin{tabular}{llcr} 
Name: & Gender: & Male & Female Age: \\
Phone: & & & Handed: \\
\hline
\end{tabular}

Education

Currently Student or Non-student:

Highest level of education obtained Years Area of study

Previous degree / diploma

NO YES: Area of study

Exclusion: Less than High School Diplama ( $<12$ years of education)

LANGUAGE

What is your first language

English learned at age Fluent in English YES \$O

Language spoken in grade school Other languages

Exclusion: Not fluent in English

HeAL.TH

Vision

Do you wear:

GLASSES: CONTACTS

NONE

Operations on your eyes?

NO YES: Specify

Exclusion: uncorrected problems with vision

Hearing Do you have any problems with your hearing? NO YES

If YES, is your hearing corrected to normal with a bearing aid? Specify:

Exclusion: uncarrected hearing problems that would interfere with narmal speech comprehension [current]

Conditions Have you ever had any of the following conditions?

$\begin{array}{llllll}\text { Stroke } & \text { NO YES: } & \text { Exclusion } & \text { Learning disability } & \text { NO YES: ADHD? YES: Exclusion } \\ \text { Tumor } & \text { NO YES: Brain? YES: Exclusion } & \text { Psychiatric illness } & \text { NO YES: Exclusion } \\ \text { Neurological diseases } & \text { NO YES: } & \text { Exclusion } & \text { Epilepsy } & \text { NO YES: Exclusion } \\ \text { Head injury } & \text { NO YES: } & \text { Exclusion } & \text { Cancer } & \text { NO YES: Last } 3 \text { yrs? YES: Exclusion } \\ \text { Concussion } & \text { NO YES: } & \text { Exclusion } & \text { High blood pressure } & \text { NO YES: Controlled? NO: Exclusion } \\ \text { Depression } & \text { NO YES: Current? YES: Exclusion } & \text { Diabetes } & \text { NO YES: Controlled? NO: Exclusion } \\ \text { Anxiety } & \text { NO YES: Current? YES: Exclusion } & \text { Thyroid disease } & \text { NO YES: Controlled? NO: Exclusion } \\ \text { Seizure } & \text { NO YES: Exclusion } & \text { Serious car accident } & \text { NO YES: Hit head? YES: Exclusion } \\ \text { Aneurysm } & \text { NO YES: } & \text { Exclusion } & \text { Been unconscious } & \text { NO YES: Exclusion }\end{array}$

Have you been taking any medications in the last six months 


\section{Appendix B}

\section{FOLSTEIN MINI MENTAL STATE EXAM}

ORIENTATION

SCORE

- What year is it?

(1) What season is it?

- What is today's date?

(prompt for month and/or date if either omitted)

- What day of the week is it? (1)

- What province are we in?

- What country are we in?

- What city are we in?

- What hospital/bldg. is this? (1)

- What floor are we on? (1)

\section{REGISTRATION}

- Now I am going to say three words. When I stop, I want you to say them after me. BUS... DOOR... ROSE (Score one point for each word correct on the first trial. Repeat until all three words are repeated correctly, and record the number of trials.) (3)

\section{ATTENTION AND CALCULATION}

- I am going to say a word. I want you to spell the word backwards. The word is 'WORLD'. (5)

\section{RECALL}

- What were those three words I had you repeat after me? (record) (3)

\section{LANGUAGE}

- What is this? (hold up a pencil) (point to a watch) And what is this? (2)

- Repeat this phrase after me: No ifs, ands, or buts. (1)

- I am going to hand you a piece of paper. I want you to take it in your right hand, fold it in half, and lay it on your lap. (hand paper only after giving all commands) (3)

- Read this aloud and do what it says. (1)

- I want you to write a complete sentence. (1)

- Copy this design as carefully as you can. (1) 


\section{Appendix C \\ Mill Hill Vocabulary Scale}

\section{Instructions}

After each number (1-34) there is a word in CAPITAL letters. Below the capitalized word there are 6 words in small print, one of which means the same as the word above. Please underline the small-print word that means the same as the word in capitals.

They start off fairly easily, but rapidly get harder - we don'f expect you to get them all right. But we do want you to try every one.

Even if you have no idea about the meaning of the word, please always underline one word simply guess if you don't know.

Take your own time, but don't spend ages on any one choice - just guess when you don't know.

1. CONNECT

$\begin{array}{ll}\text { accident } & \text { join } \\ \text { lace } & \text { bean } \\ \text { flint } & \text { field }\end{array}$

2. PROVIDE harmonize commit hurt supply annoy divide

\section{LIBERTY}

worry freedom rich serviette

forest cheerful

8. THRIVE

flourish try thrash reap

think memory

11. DWINDLE swindle pander diminish wheeze linger compare

\section{SURMOUNT}

mountain descend overcome concede appease snub

\section{STUBBORN \\ obstinate steady hopeful hollow orderly slack}

\begin{tabular}{ll} 
6. COURTEOUS & \\
dreadful & proud \\
truthful & \multicolumn{2}{c}{ short } \\
curtsey & polite
\end{tabular}

\section{PRECISE}

natural stupid

faulty grand

small exact

\section{LAVISH}

unaccountable selfish

romantic lawful

extravagant praise

15. BOMBASTIC

democratic pompous

bickering cautious

destructive anxious

\begin{tabular}{|c|c|}
\hline \multirow{3}{*}{\multicolumn{2}{|c|}{ 4. SCHOONER }} \\
\hline & \\
\hline & \\
\hline $\begin{array}{l}\text { ship } \\
\text { plant }\end{array}$ & $\begin{array}{l}\text { singer } \\
\text { scholar }\end{array}$ \\
\hline
\end{tabular}

7. RESEMBLANCE

attendance fondness

assemble repose

likeness memory

10. ELEVATE

revolve move

raise work

waver disperse

$\begin{array}{ll}\text { 13. WHIM } & \\ \text { complain } & \text { noise } \\ \text { tonic } & \text { fancy } \\ \text { wind } & \text { rush }\end{array}$

16. RECUMBENT

fugitive cumbersome

unwieldy repelling

reclining penitent 


\section{ENVISAGE \\ contemplate activate \\ surround estrange \\ enfeeble regress}

\section{PERPETRATE \\ appropriate commit \\ propitiate deface \\ control pierce}

23. AMULET
savoury jacket
flirtation
cameo

26. FECUND

esculent optative

profound prolific

sublime salic

29. VAGARY

vagabond caprice

obscurity vulgarity

evasion fallacy

32. NUGATORY

inimitable adamant

sublime contrary

numismatic trifling

\section{TRUMPERY \\ worthless heraldry \\ etiquette highest \\ amusement final}

21. LEVITY

parsimony velleity

salutary frivolity

alacrity tariff

24. QUERULOUS

astringent fearful

petulant curious

inquiring spurious

27. ABNEGATE

contradict decry

renounce execute

belie assemble

30. SPECIOUS

fallacious coeval

palatial typical

nutritious flexible

33. ADUMBRATE

foreshadow protect

detect eradicate

elaborate approach
19. GLOWER

extinguish shine disguise gloat aerate scowl

22. LIBERTINE

missionary rescuer

profligate canard

regicide farrago

25. TEMERITY

impermanence rashness

nervousness stability

punctuality submissiveness

28. TRADUCE

challenge attenuate

suspend establish

misrepresent conclude

31. SEDULOUS

rebellious dilatory

complainant diligent

seductive credulous

34. MINATORY

implacable diminutive

belittling quiescent

depository threatening 
Appendix D

Digit Symbol-Coding

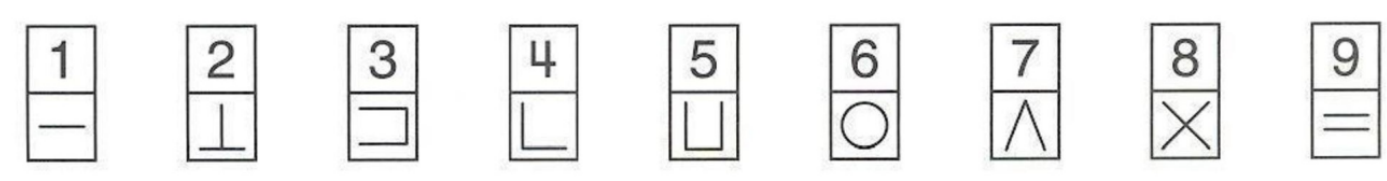

Sample Items

\begin{tabular}{|l|l|l|l|l|l|l|l|l|l|l|l|l|l|l|l|l|l|l|l|}
\hline 2 & 1 & 3 & 7 & 2 & 4 & 8 & 2 & 1 & 3 & 2 & 1 & 4 & 2 & 3 & 5 & 2 & 3 & 1 & 4 \\
\hline & & & & & & & & & & & & & & & & & & & \\
\hline
\end{tabular}

\begin{tabular}{|l|l|l|l|l|l|l|l|l|l|l|l|l|l|l|l|l|l|l|l|}
\hline 5 & 6 & 3 & 1 & 4 & 1 & 5 & 4 & 2 & 7 & 6 & 3 & 5 & 7 & 2 & 8 & 5 & 4 & 6 & 3 \\
\hline & & & & & & & & & & & & & & & & & & & \\
\hline
\end{tabular}

\begin{tabular}{|l|l|l|l|l|l|l|l|l|l|l|l|l|l|l|l|l|l|l|l|}
\hline 7 & 2 & 8 & 1 & 9 & 5 & 8 & 4 & 7 & 3 & 6 & 2 & 5 & 1 & 9 & 2 & 8 & 3 & 7 & 4 \\
\hline & & & & & & & & & & & & & & & & & & & \\
\hline
\end{tabular}

\begin{tabular}{|l|l|l|l|l|l|l|l|l|l|l|l|l|l|l|l|l|l|l|l|}
\hline 6 & 5 & 9 & 4 & 8 & 3 & 7 & 2 & 6 & 1 & 5 & 4 & 6 & 3 & 7 & 9 & 2 & 8 & 1 & 7 \\
\hline & & & & & & & & & & & & & & & & & & & \\
\hline
\end{tabular}

\begin{tabular}{|l|l|l|l|l|l|l|l|l|l|l|l|l|l|l|l|l|l|l|l|}
\hline 9 & 4 & 6 & 8 & 5 & 9 & 7 & 1 & 8 & 5 & 2 & 9 & 4 & 8 & 6 & 3 & 7 & 9 & 8 & 6 \\
\hline & & & & & & & & & & & & & & & & & & & \\
\hline
\end{tabular}

\begin{tabular}{|l|l|l|l|l|l|l|l|l|l|l|l|l|l|l|l|l|l|l|l|}
\hline 2 & 7 & 3 & 6 & 5 & 1 & 9 & 8 & 4 & 5 & 7 & 3 & 1 & 4 & 8 & 7 & 9 & 1 & 4 & 5 \\
\hline & & & & & & & & & & & & & & & & & & & \\
\hline
\end{tabular}

\begin{tabular}{|l|l|l|l|l|l|l|l|l|l|l|l|l|l|l|l|l|l|l|l|}
\hline 7 & 1 & 8 & 2 & 9 & 3 & 6 & 7 & 2 & 8 & 5 & 2 & 3 & 1 & 4 & 8 & 4 & 2 & 7 & 6 \\
\hline
\end{tabular} 


\section{Appendix E}

\section{BIS/BAS}

Each item of this questionnaire is a statement that a person may either agree with or disagree with. For each item, indicate how much you agree or disagree with what the item says. Choose only one response to each statement. Please be as accurate and honest as you can be. Respond to each item as if it were the only item. That is, don't worry about being "consistent" in your responses. Choose from the following four response options:

\section{$1=$ very true for me \\ $2=$ somewhat true for me \\ 3 = somewhat false for me \\ $4=$ very false for me}

1. A person's family is the most important thing in life.

2. Even if something bad is about to happen to me, I rarely experience fear or nervousness.

3. I go out of my way to get things I want.

4. When I'm doing well at something I love to keep at it.

5. I'm always willing to try something new if I think it will be fun.

6. How I dress is important to me.

7. When I get something I want, I feel excited and energized.

8. Criticism or scolding hurts me quite a bit.

9. When I want something I usually go all-out to get it.

10. I will often do things for no other reason than that they might be fun.

11. It's hard for me to find the time to do things such as get a haircut.

12. If I see a chance to get something I want I move on it right away.

13. I feel pretty worried or upset when I think or know somebody is angry at me.

14. When I see an opportunity for something I like I get excited right away.

15. I often act on the spur of the moment.

16. If I think something unpleasant is going to happen I usually get pretty "worked up."

17. I often wonder why people act the way they do.

18. When good things happen to me, it affects me strongly.

19. I feel worried when I think I have done poorly at something important.

20. I crave excitement and new sensations.

21. When I go after something I use a "no holds barred" approach.

22. I have very few fears compared to my friends.

23. It would excite me to win a contest.

24 . I worry about making mistakes.

\begin{tabular}{|c|c|c|c|}
\hline $\begin{array}{l}\text { Very true } \\
\text { for me }\end{array}$ & & & $\begin{array}{l}\text { Very false } \\
\text { for me }\end{array}$ \\
\hline 1 & 2 & 3 & 4 \\
\hline 1 & 2 & 3 & 4 \\
\hline 1 & 2 & 3 & 4 \\
\hline 1 & 2 & 3 & 4 \\
\hline 1 & 2 & 3 & 4 \\
\hline 1 & 2 & 3 & 4 \\
\hline 1 & 2 & 3 & 4 \\
\hline 1 & 2 & 3 & 4 \\
\hline 1 & 2 & 3 & 4 \\
\hline 1 & 2 & 3 & 4 \\
\hline 1 & 2 & 3 & 4 \\
\hline 1 & 2 & 3 & 4 \\
\hline 1 & 2 & 3 & 4 \\
\hline 1 & 2 & 3 & 4 \\
\hline 1 & 2 & 3 & 4 \\
\hline 1 & 2 & 3 & 4 \\
\hline 1 & 2 & 3 & 4 \\
\hline 1 & 2 & 3 & 4 \\
\hline 1 & 2 & 3 & 4 \\
\hline 1 & 2 & 3 & 4 \\
\hline 1 & 2 & 3 & 4 \\
\hline 1 & 2 & 3 & 4 \\
\hline 1 & 2 & 3 & 4 \\
\hline 1 & 2 & 3 & 4 \\
\hline
\end{tabular}




\section{Appendix F}

\section{The PANAS}

This scale consists of a number of words that describe different feelings and emotions. Read each item and then circle the appropriate answer next to the word. Indicate to what extent you feel this way right now at this moment.

Use the following scale to record your answers:

\begin{tabular}{|c|c|c|c|c|}
\hline 1 & 2 & 3 & 4 & 5 \\
\hline $\begin{array}{c}\text { Very slightly or } \\
\text { not at all }\end{array}$ & A little & Moderately & Quite a bit & Extremely \\
\hline
\end{tabular}

\begin{tabular}{llllll} 
1. Interested & 1 & 2 & 3 & 4 & 5 \\
\hline 2. Distressed & 1 & 2 & 3 & 4 & 5 \\
\hline 3. Excited & 1 & 2 & 3 & 4 & 5 \\
\hline 4. Upset & 1 & 2 & 3 & 4 & 5 \\
\hline 5. Strong & 1 & 2 & 3 & 4 & 5 \\
\hline 6. Guilty & 1 & 2 & 3 & 4 & 5 \\
\hline 7. Scared & 1 & 2 & 3 & 4 & 5 \\
\hline 8. Hostile & 1 & 2 & 3 & 4 & 5 \\
\hline 9. Enthusiastic & 1 & 2 & 3 & 4 & 5 \\
\hline 10. Proud & 1 & 2 & 3 & 4 & 5 \\
\hline 11. Irritable & 1 & 2 & 3 & 4 & 5 \\
\hline 12. Alert & 1 & 2 & 3 & 4 & 5 \\
\hline 13. Ashamed & 1 & 2 & 3 & 4 & 5 \\
\hline 14. Inspired & 1 & 2 & 3 & 4 & 5 \\
\hline 15. Nervous & 1 & 2 & 3 & 4 & 5 \\
\hline 16. Determined & 1 & 2 & 3 & 4 & 5 \\
\hline 17. Attentive & 1 & 2 & 3 & 4 & 5 \\
\hline 18. Jittery & 1 & 2 & 3 & 4 & 5 \\
\hline 19. Active & & 3 & 4 & 5 \\
\hline 20. Afraid & 1 & 3 & 5 \\
\hline & 1 & & 5 \\
\hline
\end{tabular}




\section{Appendix G}

\section{DASS $_{21}$}

Please read each statement and circle a number $0,1,2$ or 3 which indicates how much the statement applied to you over the past week. There are no right or wrong answers. Do not spend too much time on any statement.

The rating scale is as follows:

0 Did not apply to me at all

1 Applied to me to some degree, or some of the time

2 Applied to me to a considerable degree, or a good part of time

3 Applied to me very much, or most of the time

1 I found it hard to wind down

$\begin{array}{llll}0 & 1 & 2 & 3\end{array}$

2 I was aware of dryness of my mouth

3 I couldn't seem to experience any positive feeling at all

4 I experienced breathing difficulty (eg, excessively rapid breathing, breathlessness in the absence of physical exertion)

5 I found it difficult to work up the initiative to do things

6 I tended to over-react to situations

7 I experienced trembling (eg, in the hands)

8 I felt that I was using a lot of nervous energy

9 I was worried about situations in which I might panic and make a fool of myself

10 I felt that I had nothing to look forward to

11 I found myself getting agitated

12 I found it difficult to relax

13 I felt down-hearted and blue

14 I was intolerant of anything that kept me from getting on with what I was doing

15 I felt I was close to panic

16 I was unable to become enthusiastic about anything

17 I felt I wasn't worth much as a person

18 I felt that I was rather touchy

19 I was aware of the action of my heart in the absence of physical exertion (eg, sense of heart rate increase, heart missing a beat)

20 I felt scared without any good reason

$\begin{array}{llll}0 & 1 & 2 & 3\end{array}$

$\begin{array}{llll}0 & 1 & 2 & 3\end{array}$

$\begin{array}{llll}0 & 1 & 2 & 3\end{array}$

$\begin{array}{llll}0 & 1 & 2 & 3\end{array}$

$\begin{array}{llll}0 & 1 & 2 & 3\end{array}$

$\begin{array}{llll}0 & 1 & 2 & 3\end{array}$

$\begin{array}{llll}0 & 1 & 2 & 3\end{array}$

$\begin{array}{llll}0 & 1 & 2 & 3\end{array}$

21 I felt that life was meaningless

$\begin{array}{llll}0 & 1 & 2 & 3\end{array}$

$\begin{array}{llll}0 & 1 & 2 & 3\end{array}$

$\begin{array}{llll}0 & 1 & 2 & 3\end{array}$

$\begin{array}{llll}0 & 1 & 2 & 3\end{array}$

$\begin{array}{llll}0 & 1 & 2 & 3\end{array}$

$\begin{array}{llll}0 & 1 & 2 & 3\end{array}$

$\begin{array}{llll}0 & 1 & 2 & 3\end{array}$

$\begin{array}{llll}0 & 1 & 2 & 3\end{array}$

$\begin{array}{llll}0 & 1 & 2 & 3\end{array}$

$\begin{array}{llll}0 & 1 & 2 & 3\end{array}$

$\begin{array}{llll}0 & 1 & 2 & 3\end{array}$

$\begin{array}{llll}0 & 1 & 2 & 3\end{array}$ 


\section{References}

Aston-Jones, G., \& Cohen, J. D. (2005). An integrative theory of locus coeruleusnorepinephrine function: adaptive gain and optimal performance. Annual Review of Neuroscience, 28, 403-450.

Barkaszi, I., Takács, E., Czigler, I., \& Balázs, L. (2016). Extreme Environment Effects on Cognitive Functions: A Longitudinal Study in High Altitude in Antarctica. Frontiers in Human Neuroscience, 10, 331.

Benjamini, Y., \& Hochberg, Y. (1995). Controlling the false discovery rate: A practical and powerful approach to multiple testing. Journal of the Royal Statistical Society, Series B (Methodological), 57, 289-300.

Bouret, S., Richmond, B. J., \& Ravel, S. (2012). Complementary neural correlates of motivation in dopaminergic and noradrenergic neurons of monkeys. Frontiers in Behavioral Neuroscience, 6, 1-12

Braver, T. S. (2012). The variable nature of cognitive control: A dual mechanisms framework. Trends in Cognitive Sciences, 16, 106-113.

Braver, T. S., \& Cohen, J. D. (2000). On the control of control: The role of dopamine in regulating prefrontal function and working memory. Control of Cognitive Processes: Attention and Performance XVIII, 713-737.

Braver, T. S., Krug, M. K., Chiew, K. S., Kool, W., Westbrook, J. A., Clement, N. J., ... \& Cools, R. (2014). Mechanisms of motivation-cognition interaction: challenges and opportunities. Cognitive, Affective, \& Behavioral Neuroscience, 14, 443-472. 
Callejas, A., Lupianez, J., Funes, M. J., \& Tudela, P. (2005). Modulations among the alerting, orienting and executive control networks. Experimental Brain Research, 167, 27-37.

Carstensen, L. L., Isaacowitz, D. M., \& Charles, S. T. (1999). Taking time seriously: A theory of socioemotional selectivity. American Psychologist, 54, 165-181.

Carver, C. S., \& White, T. L. (1994). Behavioral inhibition, behavioral activation, and affective responses to impending reward and punishment: The BIS/BAS Scales. Journal of Personality and Social Psychology, 67, 319-333.

Charles, S. T., Mather, M., \& Carstensen, L. L. (2003). Aging and emotional memory: The forgettable nature of negative images for older adults. Journal of Experimental Psychology: General, 132, 310-324.

Chiew, K. S., \& Braver, T. S. (2011). Positive affect versus reward: Emotional and motivational influences on cognitive control. Frontiers in Psychology, 2, 1-10.

Chiew, K. S., \& Braver, T. S. (2013). Temporal dynamics of motivation- cognitive control interactions revealed by high-resolution pupillometry. Frontiers in Psychology, 4, 15.

Chiew, K. S., \& Braver, T. S. (2016). Reward favors the prepared: Incentive and taskinformative cues interact to enhance attentional control. Journal of Experimental psychology: Human Perception and Performance, 42, 52-66.

Chowdhury, R., Guitart-Masip, M., Lambert, C., Dayan, P., Huys, Q., Düzel, E., \& Dolan, R. J. (2013). Dopamine restores reward prediction errors in old age. Nature Neuroscience, 16, 648-653. 
Delorme, A., \& Makeig, S. (2004). EEGLAB: An open source toolbox for analysis of single-trial EEG dynamics including independent component analysis. Journal of Neuroscience Methods, 134, 9-21.

Depping, M. K., \& Freund, A. M. (2012). Normal aging and decision making: The role of motivation. Human Development, 54, 349-367.

Di Rosa, E., Mapelli, D., Arcara, G., Amodio, P., Tamburin, S., \& Schiff, S. (2017). Aging and risky decision-making: New ERP evidence from the Iowa Gambling Task. Neuroscience Letters, 640, 93-98.

Ebner, N. C., Freund, A. M., \& Baltes, P. B. (2006). Developmental changes in personal goal orientation from young to late adulthood: from striving for gains to maintenance and prevention of losses. Psychology and Aging, 21, 664-678.

Engelmann, J. B., Damaraju, E., Padmala, S., \& Pessoa, L. (2009). Combined effects of attention and motivation on visual task performance: transient and sustained motivational effects. Frontiers in Human Neuroscience, 3, 1-17.

Engelmann, J. B., \& Pessoa, L. (2014). Motivation sharpens exogenous spatial attention. Emotion, 7, 668-674.

Eppinger, B., Hämmerer, D., \& Li, S. C. (2011). Neuromodulation of reward-based learning and decision making in human aging. Annals of the New York Academy of Sciences, 1235, 1-17.

Eppinger, B., Nystrom, L. E., \& Cohen, J. D. (2012). Reduced sensitivity to immediate reward during decision-making in older than younger adults. PloS one, 7, e36953. 
Eriksen, B. A., \& Eriksen, C. W. (1974). Effects of noise letters upon the identification of a target letter in a nonsearch task. Attention, Perception, \& Psychophysics, 16, $143-149$.

Fan, J., McCandliss, B. D., Fossella, J., Flombaum, J. I., \& Posner, M. I. (2005). The activation of attentional networks. Neuroimage, 26, 471-479.

Fernandez-Duque, D., \& Black, S. E. (2006). Attentional networks in normal aging and Alzheimer's disease. Neuropsychology, 20, 133-143.

Folstein, M. F., Folstein, S. E., \& McHugh, P. R. (1975). “Mini-mental state”: a practical method for grading the cognitive state of patients for the clinician. Journal of Psychiatric Research, 12, 189-198.

Forstmann, B. U., Tittgemeyer, M., Wagenmakers, E. J., Derrfuss, J., Imperati, D., \& Brown, S. (2011). The speed-accuracy tradeoff in the elderly brain: a structural model-based approach. Journal of Neuroscience, 31(47), 17242-17249.

Galvao-Carmona, A., González-Rosa, J. J., Hidalgo-Muñoz, A. R., Páramo, D., Benítez, M. L., Izquierdo, G., \& Vázquez-Marrufo, M. (2014). Disentangling the attention network test: behavioral, event related potentials, and neural source analyses. Frontiers in Human Neuroscience, 8, 813.

Gamboz, N., Zamarian, S., \& Cavallero, C. (2010). Age-related differences in the attention network test (ANT). Experimental Aging Research, 36, 287-305.

Gilzenrat, M. S., Nieuwenhuis, S., Jepma, M., \& Cohen, J. D. (2010). Pupil diameter tracks changes in control state predicted by the adaptive gain theory of locus coeruleus function. Cognitive, Affective, \& Behavioral Neuroscience, 10, 252269. 
Hasher, L., \& Zacks, R. T. (1988). Working memory, comprehension, and aging: A review and a new view. Psychology of Learning and Motivation, 22, 193-225.

Hofmeister, J., \& Sterpenich, V. (2015). A role for the locus coeruleus in reward processing: encoding behavioral energy required for goal-directed actions. Journal of Neuroscience, 35, 10387-10389.

Isaacowitz, D. M., Wadlinger, H. A., Goren, D., \& Wilson, H. R. (2006). Selective preference in visual fixation away from negative images in old age? An eyetracking study. Psychology and Aging, 21, 40-48.

Jennings, J. M., Dagenbach, D., Engle, C. M., \& Funke, L. J. (2007). Age-related changes and the attention network task: An examination of alerting, orienting, and executive function. Aging, Neuropsychology, and Cognition, 14, 353-369.

Jimura, K., Locke, H. S., \& Braver, T. S. (2010). Prefrontal cortex mediation of cognitive enhancement in rewarding motivational contexts. Proceedings of the National Academy of Sciences, 107, 8871-8876.

Joshi, S., Li, Y., Kalwani, R. M., \& Gold, J. I. (2016). Relationships between pupil diameter and neuronal activity in the locus coeruleus, colliculi, and cingulate cortex. Neuron, 89, 221-234.

Kaufman, D. A., Sozda, C. N., Dotson, V. M., \& Perlstein, W. M. (2016). An EventRelated Potential Investigation of the Effects of Age on Alerting, Orienting, and Executive Function. Frontiers in Aging Neuroscience, 8, 99.

Kisley, M. A., Wood, S., \& Burrows, C. L. (2007). Looking at the sunny side of life age-related change in an event-related potential measure of the negativity bias. Psychological Science, 18, 838-843. 
Lange-Malecki, B., \& Treue, S. (2012). A flanker effect for moving visual stimuli. Vision Research, 62, 134-138.

Lopez-Calderon, J., \& Luck, S. J. (2014). ERPLAB: An open-source toolbox for the analysis of event-related potentials. Frontiers in Human Neuroscience, 8, 213.

Lovibond, P. F., \& Lovibond, S. H. (1995). The structure of negative emotional states: Comparison of the Depression Anxiety Stress Scales (DASS) with the Beck Depression and Anxiety Inventories. Behavioral Research and Therapy, 33, 335343.

Luck, S. J. (2014). An introduction to the event-related potential technique. MIT press.

Lustig, C., Hasher, L., \& Zacks, R. T. (2007). Inhibitory deficit theory: Recent developments in a "new view". Inhibition in Cognition, 17, 145-162.

MacLeod, J. W., Lawrence, M. A., McConnell, M. M., Eskes, G. A., Klein, R. M., \& Shore, D. I. (2010). Appraising the ANT: Psychometric and theoretical considerations of the Attention Network Test. Neuropsychology, 24, 637-651.

Mahoney, J. R., Verghese, J., Goldin, Y., Lipton, R., \& Holtzer, R. (2010). Alerting, orienting, and executive attention in older adults. Journal of the International Neuropsychological Society, 16, 877-889.

Marini, F., van den Berg, B., \& Woldorff, M. G. (2015). Reward prospect interacts with trial-by-trial preparation for potential distraction. Visual cognition, 23, 313-335.

Mather, M., \& Carstensen, L. L. (2003). Aging and attentional biases for emotional faces. Psychological Science, 14, 409-415.

Mather, M., \& Carstensen, L. L. (2005). Aging and motivated cognition: The positivity effect in attention and memory. Trends in Cognitive Sciences, 9, 496-502. 
Mather, M., \& Harley, C. W. (2016). The Locus Coeruleus: Essential for maintaining cognitive function and the aging brain. Trends in Cognitive Sciences, 20, 214226.

McConnell, M. M., \& Shore, D. I. (2011). Mixing measures: testing an assumption of the Attention Network Test. Attention, Perception, \& Psychophysics, 73, 1096-1107.

Murphy, P. R., Robertson, I. H., Balsters, J. H., \& O'Connell, R. G. (2011). Pupillometry and P3 index the locus coeruleus-noradrenergic arousal function in humans. Psychophysiology, 48, 1532-1543.

Nielsen, L., Knutson, B., \& Carstensen, L. L. (2008). Affect dynamics, affective forecasting, and aging. Emotion, 8, 318-330.

Neuhaus, A. H., Urbanek, C., Opgen-Rhein, C., Hahn, E., Ta, T. M. T., Koehler, S., ... \& Dettling, M. (2010). Event-related potentials associated with Attention Network Test. International Journal of Psychophysiology, 76, 72-79.

Pessoa, L., \& Engelmann, J. B. (2010). Embedding reward signals into perception and cognition. Frontiers in Neuroscience, 4, 17.

Petersen, S. E., \& Posner, M. I. (2012). The attention system of the human brain: 20 years after. Annual Review of Neuroscience, 35, 73-89.

Posner, M. I. (1980). Orienting of attention. Quarterly Journal of Experimental Psychology, 32, 3-25.

Posner, M. I., \& Dehaene, S. (1994). Attentional networks. Trends in neurosciences, 17(2), 75-79.

Posner, M. I., \& Petersen, S. E. (1990). The attention system of the human brain. Annual review of neuroscience, 13, 25-42. 
Rademacher, L., Salama, A., Gründer, G., \& Spreckelmeyer, K. N. (2014). Differential patterns of nucleus accumbens activation during anticipation of monetary and social reward in young and older adults. Social Cognitive and Affective Neuroscience, 9, 825-831.

Raven, J. C. (1982). Revised Manual for Raven's Progressive Matrices and Vocabulary Scale. Windsor, England: NFER Nelson.

Reed, A. E., Chan, L., \& Mikels, J. A. (2014). Meta-analysis of the age-related positivity effect: age differences in preferences for positive over negative information. Psychology and Aging, 29, 1-15.

Rosell-Negre, P., Bustamante, J. C., Fuentes-Claramonte, P., Costumero, V., Benabarre, S., \& Barrós-Loscertales, A. (2017). Monetary reward magnitude effects on behavior and brain function during goal-directed behavior. Brain imaging and behavior, 11, 1037-1049.

Salthouse, T. A., \& Miles, J. D. (2002). Aging and time-sharing aspects of executive control. Memory \& Cognition, 30, 572-582.

Samanez-Larkin, G. R., Gibbs, S. E., Khanna, K., Nielsen, L., Carstensen, L. L., \& Knutson, B. (2007). Anticipation of monetary gain but not loss in healthy older adults. Nature Neuroscience, 10, 787-791.

Sara, S. J. (2009). The locus coeruleus and noradrenergic modulation of cognition. Nature Reviews Neuroscience, 10, 211-223.

Schevernels, H., Bombeke, K., Krebs, R. M., \& Boehler, C. N. (2016). Preparing for (valenced) action: The role of differential effort in the orthogonalized go/no-go task. Psychophysiology, 53, 186-197. 
Spaniol, J., Bowen, H. J., Wegier, P., \& Grady, C. (2015). Neural responses to monetary incentives in younger and older adults. Brain Research, 1612, 70-82.

Sparrow, E. P., \& Spaniol, J. (2016). Age-related changes in decision making. Current Behavioral Neuroscience Reports, 3, 285-292.

Talsma, D., Slagter, H. A., Nieuwenhuis, S., Hage, J., \& Kok, A. (2005). The orienting of visuospatial attention: An event-related brain potential study. Cognitive Brain Research, 25, 117-129.

Townsend, J.T., \& Ashby, F. G. (1983). Stochastic modeling of elementary psychological processes. Cambridge: Cambridge University Press.

Van Dam, N. T., Sano, M., Mitsis, E. M., Grossman, H. T., Gu, X., Park, Y., ... \& Fan, J. (2013). Functional neural correlates of attentional deficits in amnestic mild cognitive impairment. PLoS One, 8, e54035.

Verhaeghen, P., \& De Meersman, L. (1998). Aging and the Stroop effect: A metaanalysis. Psychology and aging, 13, 120-126.

Wang, Y., Chan, G. L., Holden, J. E., Dobko, T., Mak, E., Schulzer, M., ... \& Stoessl, A. J. (1998). Age-dependent decline of dopamine D1 receptors in human brain: a PET study. Synapse, 30, 56-61.

Watson, D., Clark, L. A., \& Tellegen, A. (1988). Development and validation of brief measures of positive and negative affect: The PANAS scale. Journal of Personality and Social Psychology, 54, 1063-1070.

Wechsler, D. (1997). WAIS-III: Administration and scoring manual. San Antonio, TX: The Psychological Association. 
Wild-Wall, N., Falkenstein, M., \& Hohnsbein, J. (2008). Flanker interference in young and older participants as reflected in event-related potentials. Brain Research, 1211, 72-84

Williams, R. S., Biel, A. L., Dyson, B. J., \& Spaniol, J. (2017). Age differences in gain-and loss-motivated attention. Brain and Cognition, 111, 171-181.

Williams, R. S., Biel, A. L., Wegier, P., Lapp, L. K., Dyson, B. J., \& Spaniol, J. (2016). Age differences in the Attention Network Test: Evidence from behavior and event-related potentials. Brain and Cognition, 102, 65-79.

Williams, R. S., Kudus, F., Dyson, B. J., \& Spaniol, J. (2018). Transient and sustained incentive effects on electrophysiological indices of cognitive control in younger and older adults. Cognitive, Affective, \& Behavioral Neuroscience, 313-330.

Xuan, B., Mackie, M. A., Spagna, A., Wu, T., Tian, Y., Hof, P. R., \& Fan, J. (2016). The activation of interactive attentional networks. NeuroImage, 129, 308-319.

Yee, D. M., \& Braver, T. S. (2018). Interactions of motivation and cognitive control. Current Opinion in Behavioral Sciences, 19, 83-90.

Zhang, R., Hu, Z., Debi, R., Zhang, L., Li, H., \& Liu, Q. (2013). Neural processes underlying the "same"-“different" judgment of two simultaneously presented objects-an EEG study. PloS one, 8, e 